\title{
The male song of the Javan silvery gibbon (Hylobates moloch)
}

\author{
Thomas Geissmann ${ }^{1}$, Sylke Bohlen-Eyring ${ }^{2}$ and Arite Heuck ${ }^{2}$ \\ ${ }_{1}^{1}$ Anthropological Institute, University Zürich-Irchel, Winterthurerstr. 190, CH-8057 Zürich, Switzerland; \\ ${ }^{2}$ Institute of Zoology, Tierärztliche Hochschule Hannover, Germany
}

Keywords: Hylobates moloch, silvery gibbon, male song, individuality, calls, honest signal

\begin{abstract}
This is the first study on the male song of the Javan silvery gibbon (Hylobates moloch), and the first quantitative evaluation of the syntax of male solo singing in any gibbon species carried out on a representative sample of individuals. Because male gibbon songs generally exhibit a higher degree of structural variability than female songs, the syntactical rules and the degree of variability in male singing have rarely been examined. In contrast to most other gibbon species, mated silvery gibbons do not appear to produce duet song bouts but solo song bouts only, and male singing is exceptionally rare, making this study particularly challenging. For the present study, we tape-recorded and analysed several solo song bouts of eight silvery gibbon males, including both wild and captive individuals. Based on their frequency characteristics, song notes were classified into a total of 14 note types. These can be grouped into five groups (labelled A through E). The proportions of the various note types were determined individually for successive 50-note sections throughout the whole song bout. Based on changes in the proportion of different note classes and note types, we roughly identify two phases in the male song: an introductory phase, during which A and B1 notes are dominant, B3 notes are rare and $\mathrm{C}$ notes are absent, and a main song phase, during which $\mathrm{B} 3$ or $\mathrm{C}$ notes are dominant. The occurrence and the proportion of various types apparently differ among individual males, however, both in the introductory and in the main phase. We estimated song motivation by determining the "number of notes per phrase" for each 50-note segment of the song bout. In each song bout, song motivation quickly increases during the introductory phase. Song motivation may exhibit strong fluctuations during the main phase of the song, but usually remains above values of 2 notes per phrase and thus above the values observed during the introductory phase. Males appear to exhibit individual preferences in the order of different note types used in their phrases. Phrase structure was found to exhibit unusually low degrees of stereotypy and high degrees of variability. As a surprising finding of our study, male phrase variability both within and between individuals appears to be higher in $H$. moloch than in most, perhaps all, other gibbon species. This high variability appears to be a derived characteristic among the Hylobatidae. We discuss the implications of this finding for the interpretation of song function and present new and testable functional hypotheses. Our study demonstrates that song function cannot be identified for "the gibbon". Gibbon songs appear to be multifunctional, and the relevance of these functions appears to exhibit strong differences among gibbon species.
\end{abstract}

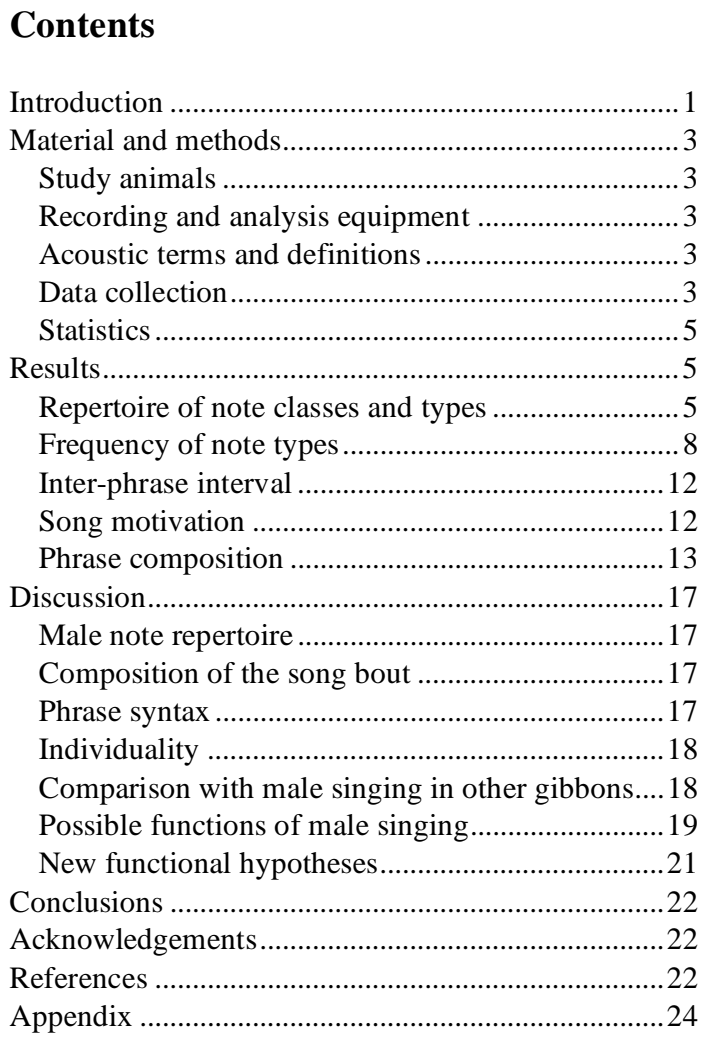

\section{Introduction}

The gibbons or small apes are distributed throughout the tropical rain forests of South-east Asia (Chivers, 2001; Geissmann, 1995; Marshall and Sugardjito, 1986). They live in monogamous, territorial family groups typically consisting of an adult pair and 1-3 immature offspring (Chivers, 1977, 2001; Leighton, 1987). All species of gibbons are known to produce elaborate, loud, long and stereotyped patterns of vocalisation usually referred to as "songs" (Geissmann, 1993, 1995, 2000; Haimoff, 1984; Marshall and Marshall, 1976). Preferentially, song bouts are produced in the early morning and have a duration of about 10-30 minutes. In most gibbon species, 
mated pairs utter their songs in the form of wellcoordinated duets. In addition, mated males of the lar group (genus Hylobates) may also produce male solo songs (Geissmann, 2002a).

The Javan silvery gibbon (Hylobates moloch) is one of only two gibbon species not known to produce duet songs (the other non-duetting species being $H$. klossii) (Geissmann, 2002a). In addition, $H$. moloch is particularly unusual among hylobatids because most of the singing is produced by females (Geissmann and Nijman, 2001; Kappeler, 1984a), and mated females appear to be the vocal " 'representative' of the family" (Kappeler, 1984a). In all other gibbons, either the opposite is true or the amounts of male and female singing are about equal (Geissmann, 2002a).

Because male singing is exceptionally rare in silvery gibbons, studying these songs was particularly challenging. During 130 days in Western Java, Kappeler heard none of his five study group males produce a song and concluded "it thus appears that territorial male moloch gibbons do not sing" (Kappeler, 1984a, p. 386). The only male song Kappeler heard in his study area was produced by a solitary male singing on the common territory boundary of two resident groups. Another similar song bout was heard outside of the study area. More recent observations in Central Java revealed that territorial males do sing, albeit rarely (Geissmann and Nijman, 2001). These authors heard choruses of male silvery gibbon song bouts occurring about once each week on average and usually before dawn. Male songs usually ended before the females started their song bouts at around dawn.

Acoustic individuality has been demonstrated to exist in several gibbon species (Dallmann and Geissmann, 2001a, b; Haimoff and Gittins, 1985; Haimoff and Tilson, 1985), but these studies have been restricted to female singing. Female songs, as a rule, are more stereotyped than male songs (Geissmann, 1995, 2002a) and, therefore, easier to analyse.

The elusive male song of $H$. moloch has not previously been analysed quantitatively. All we know of the song is based on short verbal descriptions supplemented with few short sonagrams (Kappeler, 1984a; Geissmann and Nijman, 2001). An additional song of a captive male has been described by Haimoff (1983), but this individual was later identified as a Bornean gibbon (H. muelleri) (Geissmann, 2002a).

In this study, we describe the syntax of the silvery gibbon male song based on tape-recorded songs of several captive and wild individuals. We compare the variability of male song structure within and between individuals. Our results can be used as a baseline for future studies on individuality in male gibbon singing, because the syntax and variability of male solo songs have apparently not been studied quantitatively in a representative sample of individuals for any other gibbon species.

Table 1. Origin, number of individuals and song bouts, and recording information of the material analysed in this study.

\begin{tabular}{|c|c|c|c|c|c|}
\hline Recording $^{a}$ & Recording Date & Individual & Author of Recording & $\begin{array}{l}\text { Duration of } \\
\text { Recording }\end{array}$ & $\begin{array}{l}\text { Completeness of } \\
\text { Song Bout }\end{array}$ \\
\hline Halimun & 23 Nov. 1998 & "Halimun" & B. Merker & $14 \min 43 \mathrm{~s}$ & No \\
\hline Howletts 1 & 17 Oct. 1988 & "Omar" & T. Geissmann & $38 \mathrm{~min} 46 \mathrm{~s}$ & Yes \\
\hline Howletts 2 & 18 June 1995 & "Hilo" & T. Geissmann & $35 \mathrm{~min} 52 \mathrm{~s}$ & Yes $^{b}$ \\
\hline Howletts 3 & 28 Aug. 1999 & "Lupau" & S. Bohlen-Eyring & $14 \min 42 \mathrm{~s}$ & Yes \\
\hline Jakarta 1a & 8 June 1978 & "Jakarta 1" & M. Kappeler & $7 \mathrm{~min} 31 \mathrm{~s}$ & No \\
\hline Jakarta $1 \mathrm{~b}$ & 7 June 1978 & "Jakarta 1" & M. Kappeler & $8 \min 26 s$ & No \\
\hline Jakarta 2 & 28 Jan. 2001 & "Jakarta 2" & T. Geissmann & $40 \min 45 \mathrm{~s}$ & No \\
\hline Kalejetan & 25 Aug. 1978 & "Kalejetan" & M. Kappeler & $2 \min 17 s$ & No \\
\hline Munich 1a & 21 June 1988 & "Paul" & T. Geissmann & $12 \min 15 \mathrm{~s}$ & Yes $^{c}$ \\
\hline Munich $1 \mathrm{~b}$ & 17 Oct. 1991 & "Paul" & T. Geissmann & $21 \min 03 \mathrm{~s}$ & Yes \\
\hline Munich 1c & 28 April 1995 & "Paul" & T. Geissmann & $20 \min 02 \mathrm{~s}$ & Yes \\
\hline
\end{tabular}

a Recording localities are described in the text.

b Song aborted upon the start of a solo song by the neighbouring female $H$. moloch.

c Song aborted upon the start of a solo song by the neighbouring female Nomascus leucogenys. 


\section{Material and methods}

\section{Study animals}

We analysed a total of 11 male song bouts from 8 different $H$. moloch males, as listed in Table 1. Tape-recordings were carried out at the following localities: (1) Howletts Zoo Park, Canterbury, United Kingdom; (2) Hellabrunn Zoo, Munich, Germany; (3) Ragunan Zoo, Jakarta, Java, Indonesia; (4) Kalejetan, Ujung-Kulon National Park, West Java, Indonesia; (5) Cikaniki Research Station, Gunung Halimun, West Java, Indonesia. The latter two recordings were made on wild silvery gibbons. In addition, one of us (TG) made several tape-recordings of male songs in Linggo Asri (Dieng Plateau, Central Java). Because of the large distance between the observer and the gibbons, these latter tapes were not analysed in detail, but only used for qualitative comparisons, as were additional tape-recorded male songs from Munich and Howletts.

\section{Recording and analysis equipment}

Gibbon songs were recorded with SONY WMD5M and SONY WM-D6C cassette recorders equipped with Sennheiser ME80(+K3U) and JVC MZ-707 directional microphones by us, with a UHER REPORT 4200 tape recorder and a NIVICO IVC directional microphone by M. Kappeler, and with a SONY TDC-D8 DAT-recorder and two SONY elektret microphones equipped with parabolic reflectors by B. Merker.

The sound material was digitised with a sample rate of $11 \mathrm{kHz}$ and a sample size of 16 bit. Time versus frequency displays (sonagrams) of taperecorded vocalisations were generated using the Canary software version 1.2.4 on an Apple personal computer (Power Macintosh G3). The FFT (Fast Fourier Transformation) size of the sonagrams was 2048 points with an overlap of $75 \%$ and a frame length of 1024 points (frequency resolution $=5.383 \mathrm{~Hz})($ Charif et al., 1995).

\section{Acoustic terms and definitions}

A note is defined as "any single continuous sound of any distinct frequency (pitch) or frequency modulation, which may be produced by either an inhaled or exhaled breath" (Haimoff, 1984, p. 335).

Song notes may occur either single or in more or less brief series, which are termed phrases and figures here. A phrase is a larger, loose collection of several notes preferentially uttered in combination. Intra-phrase intervals are, by definition, shorter than inter-phrase intervals. Short, stereotyped sets of notes which may facultatively occur within phrases are termed figures (sensu Haimoff, 1984).

A song is what fulfils the criteria set forth by Thorpe (1961, p. 15): "What is usually understood

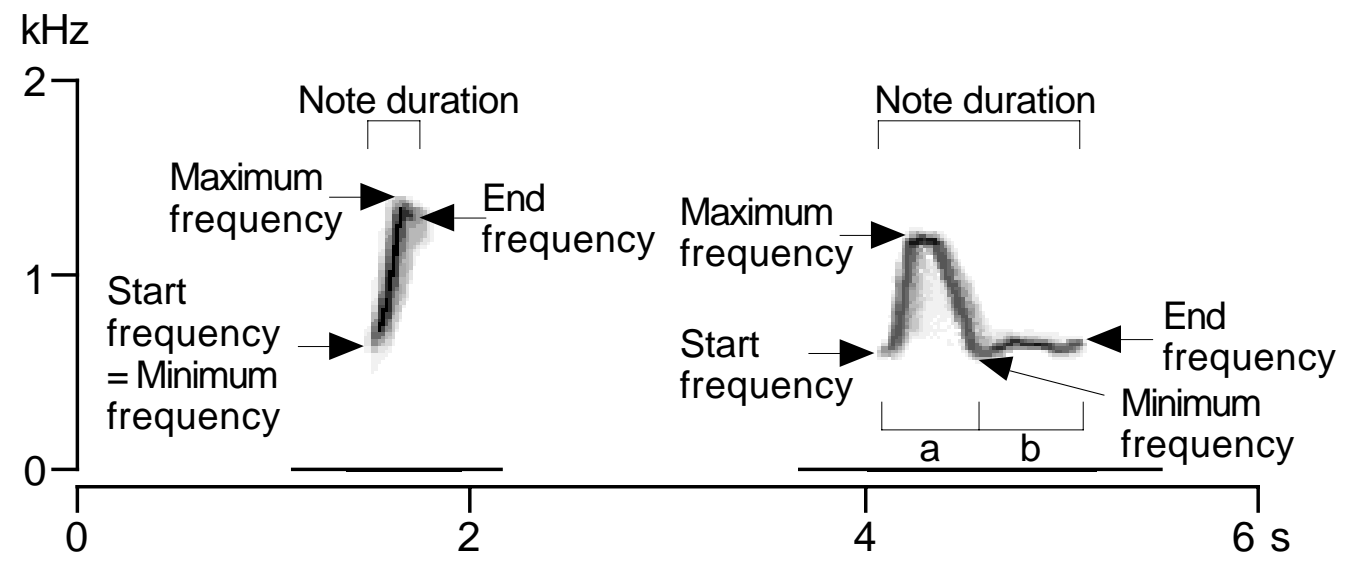

Fig. 1. Sonagram of two male song notes (a wa note and a chevron note), illustrating the measurements taken during this study. In the chevron note, "a" indicates the main or chevron part of the note, and "b" indicates the facultative end part. 
Table 2. Note measurements determined during the present study. Each cell includes mean value \pm standard deviation, range, number of individuals and (in parenthesis) the total number of notes measured (Individuals included: Halimun, Howletts 1, Howletts 2, Jakarta 1, Jakarta 2, Kalejetan, Munich).

\begin{tabular}{|c|c|c|c|c|c|}
\hline $\begin{array}{l}\text { Note } \\
\text { type }\end{array}$ & Duration (s) & Start frequency $(\mathrm{kHz})$ & End frequency $(\mathrm{kHz})$ & $\begin{array}{l}\text { Minimum frequency } \\
(\mathrm{kHz})\end{array}$ & $\begin{array}{l}\text { Maximum frequency } \\
(\mathrm{kHz})\end{array}$ \\
\hline \multirow[t]{3}{*}{ A } & $0.178 \pm 0.075$ & $0.647 \pm 0.066$ & $0.675 \pm 0.133$ & $0.593 \pm 0.075$ & $0.714 \pm 0.094$ \\
\hline & $0.106-0.450$ & $0.529-0.758$ & $0.388-0.952$ & $0.388-703$ & $0.529-0.952$ \\
\hline & $7(20)$ & $7(20)$ & $7(20)$ & $7(20)$ & $7(20)$ \\
\hline \multirow[t]{3}{*}{ B1 } & $0.252 \pm 0.068$ & $0.630 \pm 0.040$ & $0.884 \pm 0.072$ & $0.627 \pm 0.039$ & $0.896 \pm 0.071$ \\
\hline & $0.151-0.410$ & $0.551-0.700$ & $0.777-0.998$ & $0.551-0700$ & $0.784-0.998$ \\
\hline & $6(18)$ & $6(18)$ & $6(18)$ & $6(18)$ & $6(18)$ \\
\hline \multirow[t]{3}{*}{ B2 } & $0.294 \pm 0.045$ & $0.642 \pm 0.046$ & $1.152 \pm 0.081$ & $0.641 \pm 0.046$ & $1.173 \pm 0.088$ \\
\hline & $0.222-0.386$ & $0.539-0.700$ & $1.010-1.258$ & $0.539-0.700$ & $1.010-1.278$ \\
\hline & $6(18)$ & $6(18)$ & $6(18)$ & $6(18)$ & $6(18)$ \\
\hline \multirow[t]{3}{*}{ B3 } & $0.305 \pm 0.056$ & $0.659 \pm 0.048$ & $1.298 \pm 0.109$ & $0.657 \pm 0.048$ & $1.380 \pm 0.073$ \\
\hline & $0.240-0.485$ & $0.537-0.700$ & $1.070-1.514$ & $0.537-0.700$ & $1.301-1.522$ \\
\hline & $5(15)$ & $5(15)$ & $5(15)$ & $5(15)$ & $5(15)$ \\
\hline \multirow[t]{3}{*}{ B4 } & $0.259 \pm 0.060$ & $0.772 \pm 0.052$ & $1.110 \pm 0.209$ & $0.771 \pm 0.053$ & $1.151 \pm 0.199$ \\
\hline & $0.142-0.374$ & $0.714-0.890$ & $0.824-1.537$ & $0.714-0.890$ & $0.875-1.537$ \\
\hline & $5(15)$ & $5(15)$ & $5(15)$ & $5(15)$ & $5(15)$ \\
\hline \multirow[t]{3}{*}{$\mathrm{C} 1$} & $0.486 \pm 0.127$ & $0.705 \pm 0.094$ & $0.673 \pm 0.094$ & $0.654 \pm 0.079$ & $0.955 \pm 0.033$ \\
\hline & $0.309-0.722$ & $0.529-0.849$ & $0.520-0.844$ & $0.520-0.799$ & $0.890-1.000$ \\
\hline & $6(16)$ & $6(16)$ & $6(16)$ & $6(16)$ & $6(16)$ \\
\hline \multirow[t]{3}{*}{$\mathrm{C} 2$} & $0.511 \pm 0.119$ & $0.748 \pm 0.113$ & $0.719 \pm 0.110$ & $0.701 \pm 0.098$ & $1.199 \pm 0.280$ \\
\hline & $0.317-0.715$ & $0.558-0.980$ & $0.558-0.980$ & $0.558-0.918$ & $0.756-2.001$ \\
\hline & $6(17)$ & $6(17)$ & $6(17)$ & $6(17)$ & $6(17)$ \\
\hline \multirow[t]{3}{*}{$\mathrm{C} 3$} & $0.834 \pm 0.137$ & $0.715 \pm 0.103$ & $0.787 \pm 0.149$ & $0.672 \pm 0.074$ & $1.264 \pm 0.294$ \\
\hline & $0.560-1.096$ & $0.558-0.910$ & $0.558-1.082$ & $0.558-0.809$ & $0.758-1.990$ \\
\hline & $6(18)$ & $6(18)$ & $6(18)$ & $6(18)$ & $6(18)$ \\
\hline \multirow[t]{3}{*}{$\mathrm{C} 4$} & $0.778 \pm 0.156$ & $0.725 \pm 0.122$ & $0.692 \pm 0.097$ & $0.655 \pm 0.078$ & $1.233 \pm 0.171$ \\
\hline & $0.616-1.071$ & $0.606-1.024$ & $0.534-0.839$ & $0.534-0.810$ & $0.994-1.551$ \\
\hline & $5(15)$ & $5(15)$ & $5(15)$ & $5(15)$ & $5(15)$ \\
\hline \multirow[t]{3}{*}{$\mathrm{C} 5$} & $0.712 \pm 0.087$ & $0.672 \pm 0.084$ & $1.135 \pm 0.174$ & $0.668 \pm 0.085$ & $1.321 \pm 0.327$ \\
\hline & $0.541-0.770$ & $0.611-0.849$ & $0.922-1.353$ & $0.611-0.849$ & $0.982-1.970$ \\
\hline & $3(7)$ & $3(7)$ & $3(7)$ & $3(7)$ & $3(7)$ \\
\hline \multirow[t]{3}{*}{ C6 } & $0.757 \pm 0.093$ & $0.692 \pm 0.104$ & $0.880 \pm 0.199$ & $0.672 \pm 0.076$ & $1.136 \pm 0.361$ \\
\hline & $0.608-0.914$ & $0.551-0.950$ & $0.581-1.177$ & $0.551-0.772$ & $0.102-1.473$ \\
\hline & $4(12)$ & $4(12)$ & $4(12)$ & $4(12)$ & $4(12)$ \\
\hline \multirow[t]{3}{*}{ C7 } & $0.652 \pm 0.111$ & $0.68 \pm 0.101$ & $0.674 \pm 0.121$ & $0.632 \pm 0.085$ & $1.077 \pm 0.174$ \\
\hline & $0.475-0.859$ & $0.510-0.836$ & $0.530-0.956$ & $0.510-0.829$ & $0.879-1.444$ \\
\hline & $6(16)$ & $6(16)$ & $6(16)$ & $6(16)$ & $6(16)$ \\
\hline \multirow[t]{3}{*}{ D } & $0.621 \pm 0.213$ & $0.718 \pm 0.072$ & $0.682 \pm 0.116$ & $0.649 \pm 0.093$ & $0.801 \pm 0.094$ \\
\hline & $0.339-0.912$ & $0.600-0.802$ & $0.443-0.814$ & $0.443-0.765$ & $0.600-0.895$ \\
\hline & $4(10)$ & $4(10)$ & $4(10)$ & $4(10)$ & $4(10)$ \\
\hline \multirow[t]{3}{*}{$E$} & $0.238 \pm 0.093$ & $0.968 \pm 0.16$ & $0.810 \pm 0.154$ & $0.808 \pm 0.153$ & $1.064 \pm 0.169$ \\
\hline & $0.114-0,404$ & $0.710-1.232$ & $0.577-1.114$ & $0.577-1.114$ & $0.794-1.325$ \\
\hline & $6(16)$ & $6(16)$ & $6(16)$ & $6(16)$ & $6(16)$ \\
\hline
\end{tabular}

by the term song is a series of notes, generally of more than one type, uttered in succession and so related as to form a recognisable sequence or pattern in time", or, a song is a succession of phrases with non-random succession probability ("Strophenfolgen mit nicht-zufälliger Folgewahrscheinlichkeit", Tembrock, 1977, p. 33). Song bouts are separated from each other by an arbitrarily defined interval of at least 5 minutes.
Some authors have referred to individual phrases within a song bout as "songs" (e.g. Marshall and Sugardjito, 1986). We follow Geissmann's (2000) recommendation using the term "phrase" instead, in order to make it clear whether one is talking about a mere collection of notes (usually shorter than 1 minute), or about a song bout (i.e. a collection of phrases, with an overall duration of several minutes). 


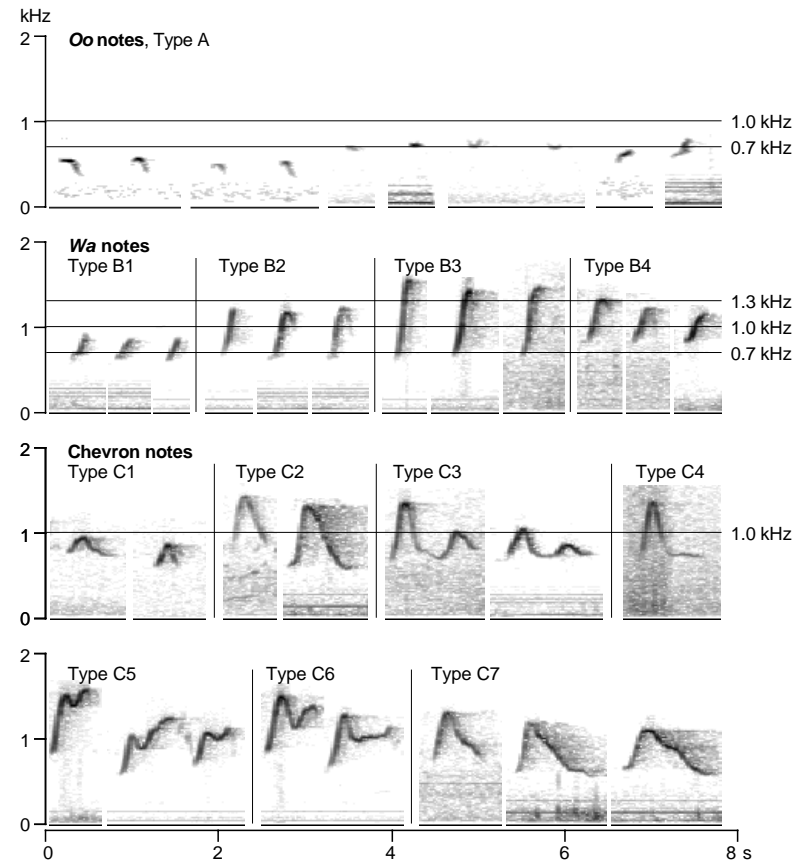

Fig. 2. Sonagrams of the various note types recognised in this study: oo notes (type A), wa notes (types B1-B4), chevron notes (types C1-C7), variable notes (type D), and inspiration notes (type $\mathrm{E}$, each inspiration note is embedded in a wa-aawa figure or a related figure consisting of three notes). On separate lines, examples of trill figures and variable figures are shown. Individual inspiration notes are identified by arrows.

\section{Data collection}

We took the following measurements on sonagraphed notes of the male song: (1) note starting frequency, (2) note maximum frequency, (3) note minimum frequency, (4) note end frequency, and (5) note duration. The variables are indicated in Figure 1. All frequency measurements were taken on the fundamental frequency of notes, which was also the dominant frequency band in all notes examined.

In order to analyse phrase composition, we selected 50 phrases from the central section of each song bout, excluding phrases with less than three notes.

\section{Statistics}

Statistical calculations were carried out using StatView 5.0 software on a G3 Power Macintosh. Non-parametric statistical tests were adapted from Siegel and Castellan (1988). All tests are twotailed, with a significance level of 0.05 . The relationship between the proportion of different

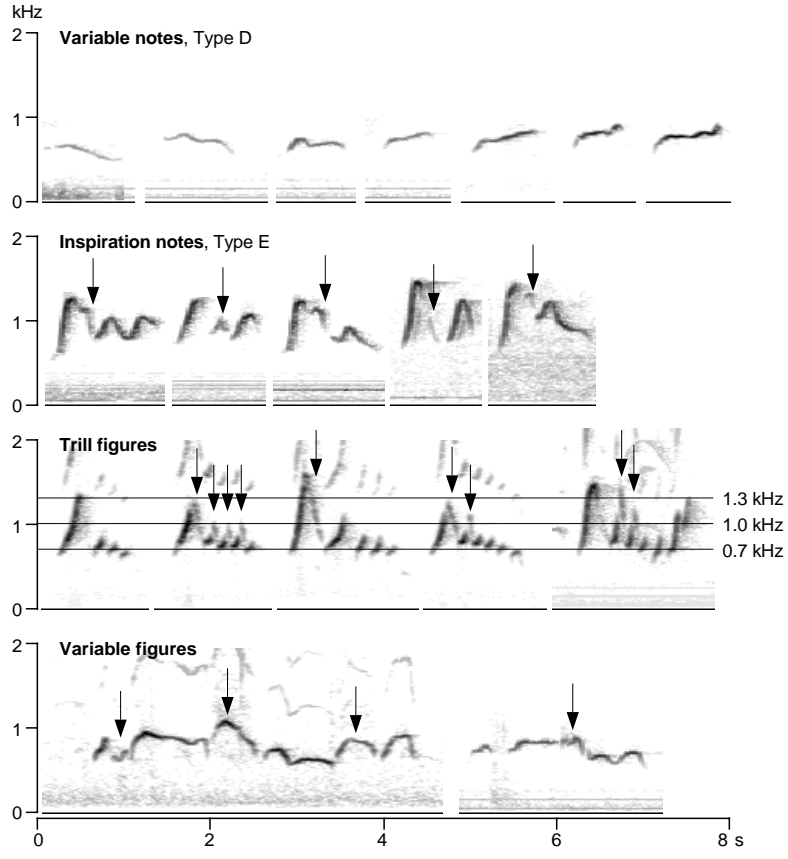

Fig. 2. (ctd).

note types and song motivation (here defined as the number of notes per phrases) during a song bout was determined with Kendall rank-order correlation coefficients (Tau). The proportions of note types in the song repertoires were compared among individual gibbons using one-way ANOVA followed by Scheffé's post-hoc test. The proportions of the most common note sequences occurring in song phrases were compared among individual gibbons using minimum discrimination information statistics (Sachs, 1984, p. 377-378). This method was chosen instead of contingency tests because it allows for a correction for empty cells, whereas the latter should not be used if more than $20 \%$ of the cells have an expected frequency of less than 5 and if any cell has an expected frequency of less than 1 (Siegel and Castellan, 1988, p. 199).

\section{Results}

\section{Repertoire of note classes and types}

Based on the frequency structure, various note classes and types can be differentiated both when listening to the songs and when examining the sonagrams of male silvery gibbons. These are de- 
fined and described below. Duration and frequency measurements were taken on three representative notes of each note type per individual. Summary measurements (mean, standard deviation, range) are presented in Table 2. In addition, the table lists the number of gibbons and the number of notes that were available for the measurements. Because not all individuals use every note type in their song bouts, the number of individuals studied may differ between note types in the table. Typical sonagrams of all note types and classes are shown in Figure 2.

Based on their different mechanisms of utterance, we first differentiate between expiration notes and inspiration notes (i.e. notes which are produced during exhalation and during breath intake, respectively). As there is no intermediate option between these two forms of vocalisation, the two forms cannot, by definition, grade into each other and are, therefore, identified as two different note classes. Expiration notes represent the large majority of the song repertoire.

Expiration notes can be further divided in a number of note types. They represent a graded system, and intermediate forms can be found among the different types. Yet, because some forms are particularly common, we identified them as different note types, although these divisions remain arbitrary. Based on similarity, expiration note types are combined into four basic groups: oo notes (1 type), wa notes (4 types), chevron notes (7 types) and variable notes (1 type). Only one type of inspiration note is recognised in this study.

\section{Oo notes}

The oo notes (Type A) are the most simple expiration notes in the male song repertoire, exhibiting the lowest intensity, the shortest duration $(0.2 \pm 0.1$ s) and the smallest amount of frequency modulation (Figure 2). The fundamental frequency is below $1 \mathrm{kHz}$. Oo notes exhibit only a moderate amount of frequency modulation, but the note shape in the sonagram is very variable: We found oo notes of increasing, decreasing or stable frequency. More complex sonagram structures - such as $u$-shaped or $n$-shaped notes or notes which begin with stable frequency but sharply go down at the end of the note - also occur. Oo notes are preferentially uttered at the beginning of the male song bout, but also occur during mild disturbances and moderate excitement outside of the song context.
During song bouts, notes may gradually change from $o o$ notes into $w a$ notes (see below).

\section{Wa notes}

Following Kappeler (1984a), the most common group of expiration notes are termed $w a$ notes. They are short like, but louder than, oo notes and characterised by a fast frequency increase. Starting frequency and minimum frequency always coincide in $w a$ notes. After reaching the maximum frequency near the end of the note, a terminal frequency decrease is absent or slight, amounting to less than half of the preceding frequency increase. Wa notes are very variable in their end and maximum frequencies. We distinguish between four different note types (Figures 2), which we term B1, B2, B3 and B4 in the following text.

Note type B1 comprises $w a$ notes of relatively moderate frequency modulation. Notes have a starting frequency of about $0.7 \mathrm{kHz}$ or below, and reach a maximum frequency of $1 \mathrm{kHz}$ or less. Note type B2 resembles B1, but the maximum frequency ranges from above $1 \mathrm{kHz}$ up to $1.3 \mathrm{kHz}$. Note type B3 comprises the wa notes with the highest amount of frequency modulation. This note type resembles $\mathrm{B} 1$, but the maximum frequency ranges from above $1.3 \mathrm{kHz}$ to about 1.5 kHz. Note type B4 includes $w a$ notes with a relatively high starting frequency (i.e. above 0.7 $\mathrm{kHz}$ ). The maximum frequency is variable and can rise to about $1.5 \mathrm{kHz}$.

The trill is a particularly stereotyped figure (i.e. a song unit intermediate between single notes and phrases). Trills are short bursts of three to five B1 notes with very short intervals. Often, the trill exhibits a distinct decrease in minimum frequency, maximum frequency and frequency range from the first to the last trill note. Individual trill notes may or may not be followed by inspiration notes (described below). Trills usually are preceded by a B2 or B3 note, also with facultative inspiration note.

\section{Chevron notes}

The third group of note types comprises those notes which have been termed wa-oo and wa-oowa notes by Kappeler (1984 a) and are referred to as chevron notes in the present study. All chevrons begin with rising frequency, then, after reaching a peak, frequency decreases again. Chevron notes differ in their frequency structure 
and duration. Based on their shape in the sonagram, some chevron notes exhibit two distinct parts. The first part of the note (a) consists of the chevron proper described above. The second part (b) is the drawn-out tail of the chevron (Figure 1). The tail's frequency structure is particularly variable. Chevron notes are introduced relatively late during the song bout, after the wa notes. Chevron notes represent the most characteristic vocalisations in the song of male silvery gibbons, but are absent or very rare in female song bouts. Individual males appear to differ strongly in their use of chevron notes in general and of certain types of chevron notes in particular. We differentiate between seven types of chevron notes in $H$. moloch (Figure 2), which we term C1, C2, $\mathrm{C} 3$ and so on in the following text.

Note type $\mathrm{C} 1$ is of a simple chevron form in the sonagram; a tail end is absent. This note type reaches a maximum frequency of $1 \mathrm{kHz}$ or less. Note type $\mathrm{C} 2$ resembles $\mathrm{C} 1$, but its maximum frequency is situated above $1 \mathrm{kHz}$. Note type $\mathrm{C} 3$ is a chevron with a tail end. The latter is of chevron form, too, with its own peak frequency. After the tail peak, the frequency descends to about the starting level for the second time. Note type C4 resembles $\mathrm{C} 3$, but the frequency remains nearly unmodulated in the tail end. Note type C5 also is a chevron with a tail end. After reaching the first peak of the chevron, the frequency descends only moderately and does not reach the level of the starting frequency. In the tail end, the frequency rises again and reaches or even surpasses the maximum frequency of the first peak. Note type C6 resembles $\mathrm{C} 5$, but the frequency rise in the tail end is more moderate and does not reach the maximum frequency of the first peak. Note type C7 is a simple chevron resembling $\mathrm{C} 2$, but the frequency decrease occurs much more slowly than the initial increase.

\section{Variable notes}

The fourth group is termed variable notes and includes only one note type, D. It comprises all expiration notes which are neither wa notes nor chevron notes. Notes of this type are extremely variable (Figure 2). Further partitioning of this group would easily be possible but was not found useful considering its rarity in the song bout. Variable notes are long $(0.6 \pm 0.2 \mathrm{~s})$ and of very moderate frequency modulation $(0.3 \mathrm{kHz}$ or less).
The direction of the frequency modulation is variable; the frequency may rise, drop or change repeatedly.

The variable figure (Figure 2) is not a single note, but a cluster of more than three notes, with extremely short intervals and with a total duration of $1.5 \pm 0.3 \mathrm{~s}$. All note types of the male song repertoire may occur in these rapid note sequences, but variable notes and inspiration notes are most prominent. Both the degree and the direction of frequency modulations are very variable in these figures. Intervals may be so short that the number of individual notes uttered in a series can sometimes not be determined reliably. Therefore, variable figures were not broken down into single notes for the note counts of this study (see below) but simply recorded as one unit.

\section{Inspiration notes}

This note class also is variable in its frequency structure, but most commonly exhibits an either decreasing or chevron shape. Despite the structural variability of inspiration notes, only one type is recognised here (type E). A further partitioning of this class did not appear to be useful because of its rarity. Often, an inspiration note immediately follows a $w a$ note (forming a socalled wa-aa figure), or appears to link two expiration notes together (forming a wa-aa-wa figure). In these figures, intervals between notes are very short (the second sonagram of an E note in Figure 2 shows a typical $w a-a a$-wa figure). Particularly fast alternations of B1 and E notes can occur in trill figures (described above). Inspiration notes are often less loud than the accompanying $w a$ notes. The so-called variable figures (see above) may also include inspiration notes.

\section{Individuality in the note repertoire}

Not all note types were used by all males (at least not in the song material available for this study), as listed in Table 3. For instance, the Howletts 2 male was lacking types $\mathrm{C} 4$ and $\mathrm{C} 5$, Howletts 3 was lacking $\mathrm{C} 3, \mathrm{C} 4, \mathrm{C} 5$, and $\mathrm{C} 6$, and the song bout of the Halimun male did not include note type D. Similarly, the variable figure did not occur in the song of the Howletts 3 and Halimun males. Trill figures were even less common. As a regular component of the song repertoire, they only occurred in the song of the Jakarta 2 male. They 
occurred infrequently in the songs of the Munich male, and only one poorly-expressed trill was found in the song of the Howletts 1 male.

\section{Frequency of note types}

The frequency distributions of the various note types provide first insights into the rules by which male silvery gibbons build up their song bouts. As shown below, at least two distinct phases can roughly be distinguished in the male song bout: a build-up or introductory phase and a main phase.

In order to monitor changes in the proportion of notes types in various stages of a male song bout, we divided each song bout in 50-note segments and determined the proportion of all note types for each segment. Not all segments comprise exactly 50 notes, because we avoided splitting phrases (described below) into different segments. A and B1 notes were pooled in this part of the analysis.

Figure 3 shows the relative frequency of all note types in the course of song bouts of our study animals. The song bouts of the Halimun, Jakarta 1, Jakarta 2 and Kalejetan males were not tape-recorded in their entirety and may lack the build-up phase of the song bout. In order to facilitate comparison, the frequency distributions of the incomplete song bouts are shown in separate parts of Figure 3.

The proportion of most note types changes markedly during the song bout. The amount and direction of these changes differ among note types. The proportion of note types $\mathrm{A}+\mathrm{B} 1$, for instance, tends to decrease during song bouts. Whereas these two note types make up between $37-92 \%$ of the first 50 notes in the introductory phase of all completely-recorded song bouts, the proportion decreases during the course of the song to levels below $20 \%$ and eventually approaches or even reaches zero, although the proportion may go up again towards the end of the song (Howletts 3 ) or fluctuate around $15 \%$ during the second half of the song bout (Howletts 2). In the incompletely recorded song bouts, this trend cannot be recognised clearly, because the build-up part is partly or completely missing. Yet, a decrease in the proportions of note types $\mathrm{A}+\mathrm{B} 1$ can also be observed in each of the incomplete song bouts except in the Jakarta 2 male, which exhibits strong fluctuations around $15 \%$ in these note proportions during the whole tape-recording.

The proportion of note type B2 also tends to decrease somewhat during the course of the song bout, but the decrease is less pronounced than in note types $\mathrm{A}+\mathrm{B} 1$, and the proportion appears to exhibit strong individual differences. During the

Table 3. Occurrence of note types and some figures in the songs of each study animal, based on all available tape-recorded material. ${ }^{\text {a }}$

\begin{tabular}{|c|c|c|c|c|c|c|c|c|}
\hline $\begin{array}{l}\text { Note } \\
\text { type }^{\text {b }}\end{array}$ & Halimun & Howletts 1 & Howletts 2 & Howletts 3 & Jakarta 1 & Jakarta 2 & Kalejetan $^{c}$ & Munich \\
\hline A & + & + & + & + & + & + & + & + \\
\hline B1 & + & + & + & + & + & + & + & + \\
\hline B2 & + & + & + & + & + & + & + & + \\
\hline B3 & + & + & + & + & + & + & + & + \\
\hline B4 & + & + & + & + & $(+)$ & - & + & + \\
\hline $\mathrm{C} 1$ & + & + & + & + & + & + & + & + \\
\hline $\mathrm{C} 2$ & + & + & + & + & + & + & + & + \\
\hline C3 & + & + & + & + & + & + & + & + \\
\hline $\mathrm{C} 4$ & (+) & + & $(+)$ & + & + & $(+)$ & + & + \\
\hline C5 & $(+)$ & + & - & - & $(+)$ & + & + & - \\
\hline C6 & + & - & + & - & + & + & + & + \\
\hline C7 & + & + & + & + & + & + & + & + \\
\hline D & - & + & + & + & + & $(+)$ & + & $(+)$ \\
\hline E & + & + & + & + & + & + & + & + \\
\hline $\begin{array}{l}\text { Figure } \\
\text { type }\end{array}$ & & & & & & & & \\
\hline Trill $\mathrm{f}$. & - & $(+)$ & - & - & - & + & - & $(+)$ \\
\hline $\begin{array}{l}\text { Vari- } \\
\text { able f. }\end{array}$ & - & + & + & - & + & + & - & $(+)$ \\
\hline
\end{tabular}

${ }^{a}$ Symbols: $+=$ present, $(+)=$ very rare, less than $0.5 \%$ of the song notes, $-=$ absent

${ }^{\mathrm{b}} \mathrm{f}$. = figure

${ }^{c}$ Absence of some note types in this male may be due to the shortness of the tape-recorded song excerpt (2min $17 \mathrm{~s}$, see Table 1$)$. 
first 200 notes, the average proportions for Howletts 1, Howletts 3 and Munich are at $30-42 \%$, whereas the averages are lower in the remainder of the song bout (27-34\%). In the Howletts 2 male, however, this note type remains virtually absent during the first quarter of the song bout. Only later, the proportion rises to an average level of about $10 \%$, and a maximum value of $22 \%$ is reached only in the last third of the song bout. In the available song excerpts of the Jakarta 1 male, on the other hand, B2 notes proportions exhibit an average level of about $50 \%$ and never decrease below $45 \%$.

In contrast to $\mathrm{A}, \mathrm{B} 1$ and $\mathrm{B} 2$ notes, the proportion of B3 notes continually rises during the course of most song bouts. Whereas this note type makes up less than $2 \%$ at the beginning of the song bout, its proportion usually rises to a value of more than $20 \%$ within the first 400 notes of the song bout (Howletts 1, Howletts 3, Munich) or later (Howletts 2). The increase in note type B3 appears to correlate with the decrease in note type B1.

The appearance of chevron notes appears to coincide with the increase of the B3 note proportion and the decrease of the B1 note proportion. Chevron or $\mathrm{C}$ notes are never produced at the beginning of a song bout (exception: $4 \%$ in Howletts 1). The proportion of $\mathrm{C}$ notes rises to

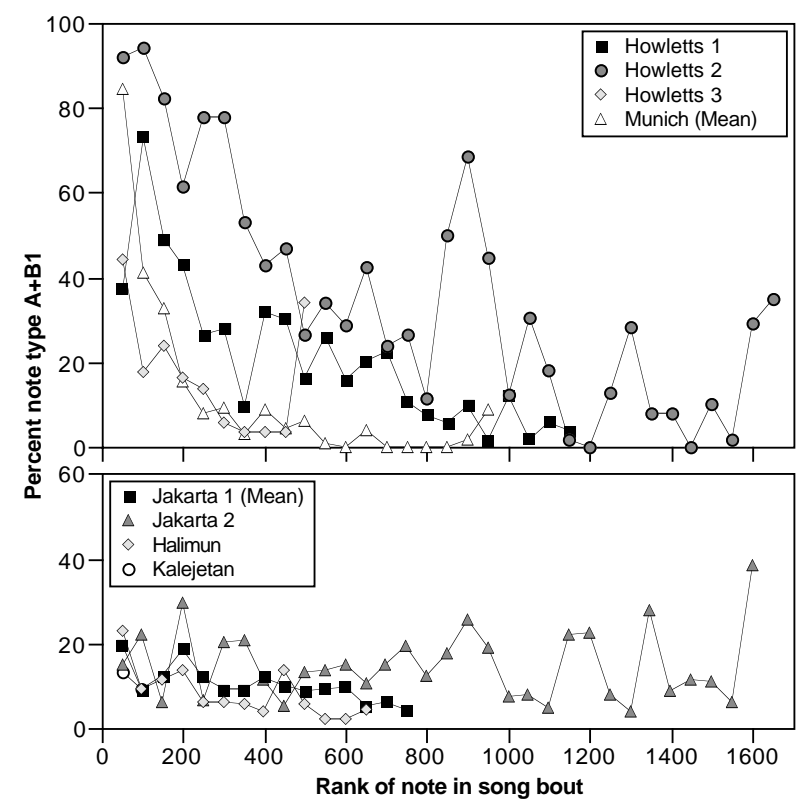

Fig. 3. Changing proportions of different note types in consecutive 50-note sections of the male song bouts of Hylobates moloch. The Halimun, Jakarta 1, Jakarta 2 and Kalejetan males are plotted separately, because the beginning of their song bouts was not recorded on tape. The resulting twin graphs show proportions of note types A+B1, B2, B3, B4, C, $\mathrm{D}$, and $\mathrm{E}$, respectively. higher levels within the first $250-400$ notes. These higher levels appear to be strongly individualspecific, ranging from about $10 \%$ (Howletts 1, Howletts 2, Halimun), $17 \%$ (Munich), 20\% (Howletts 3), 25\% (Jakarta 1), 57\% (Kalejetan), to $70 \%$ (Jakarta 2). The respective proportions of the various variants of chevron notes (C1 - C7) do not surpass $15 \%$, except $\mathrm{C} 3$ notes in the Jakarta 2 male (20\%).

The other note types defined in this study (B4, $\mathrm{D}$ and E) are much less common and, therefore, exhibit less obvious trends in their frequency distribution during the song bout. In contrast to note types $\mathrm{A}+\mathrm{B} 1, \mathrm{~B} 2, \mathrm{~B} 3$ and $\mathrm{C}$, their proportions rarely increase above $20 \%$. Notable exceptions are the high proportions of B4 notes in Howletts 2 and Halimun, and of inspiration or $\mathrm{E}$ notes in the Halimun male, which amounts to an average of $19 \%$ for the whole tape-recording and which reaches a maximum value of $34 \%$ before the end of the song bout. In the complete song bouts, inspiration notes are rare or absent at the beginning, and their frequency slightly increases with increasing song activity.

Males also appear to differ in their preferences for certain chevron notes (Table 4). For example, note type C6 was a preferred chevron type of Howletts male 2 but was never produced by Howletts males 1 and 3 .

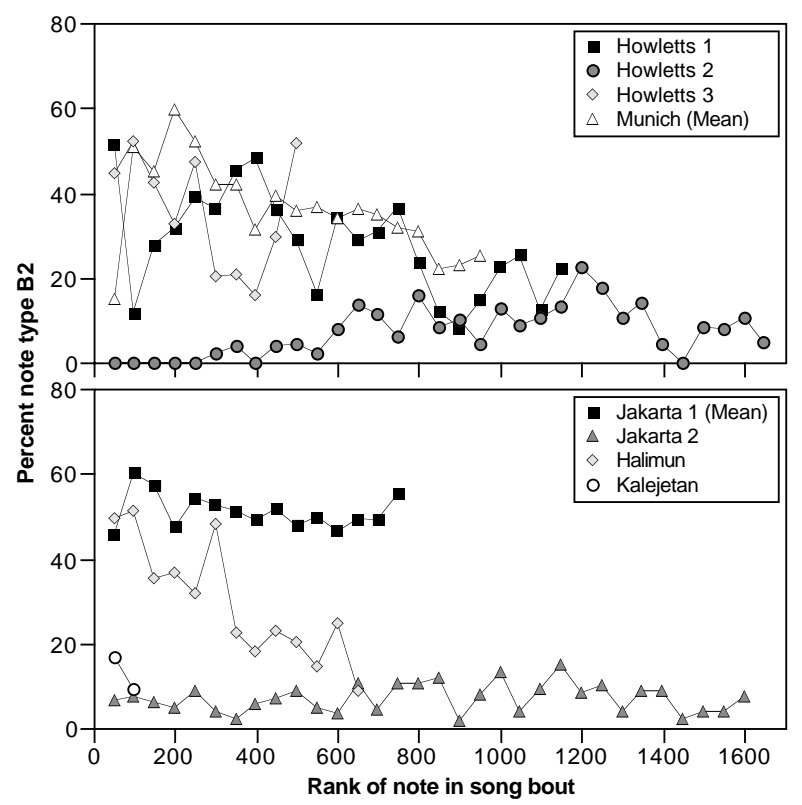

Fig. 3. (ctd.) 


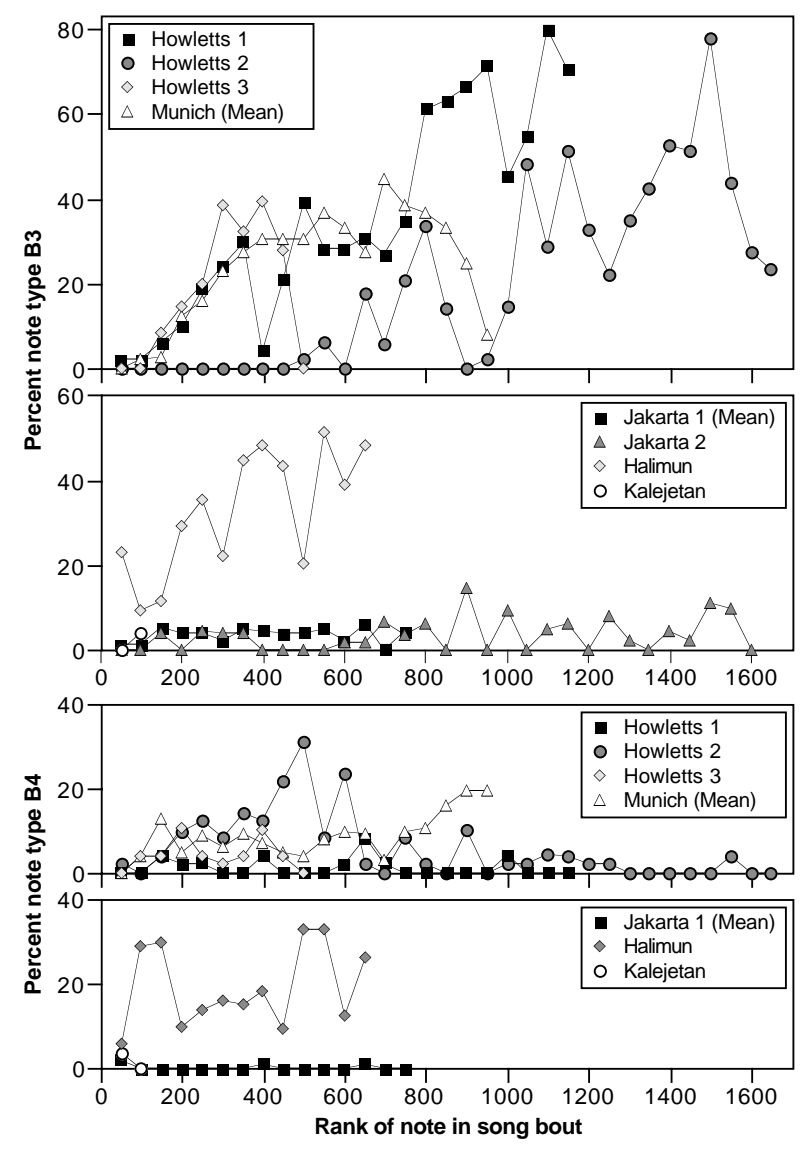

Fig. 3. (ctd.)

C5 was a preferred chevron type of Jakarta male 1 , but was never produced by Jakarta male 2 (Table 4).

Inspiration notes (type E) are introduced at about the same time as, but remain less common than, $\mathrm{B}$ and $\mathrm{C}$ notes (except in the Halimun male, which uses $\mathrm{E}$ notes more frequently than $\mathrm{C}$ notes). Trills also occur only during the main part of the song bout, but among our study males, only the Jakarta 2 male frequently produced these conspicuous figures. This figure was produced very rarely by the Munich male (only 4 occurrences in 4 song bouts) and once by the Howletts male 1. In all other males, the trill was not heard at all.

In summary, the note repertoire of the male song of $H$. moloch is structured as follows: The song bout begins with soft oo notes (type A) which gradually change into low frequency wa notes (types B1 and B2). We use the term build-up phase or introductory phase for this part of the song bout, which consists almost entirely of $o o$ notes and low frequency $w a$ notes. After about 150 to 250 notes, high frequency wa notes (types B3 and B4) and chevron notes (type C) are gradu
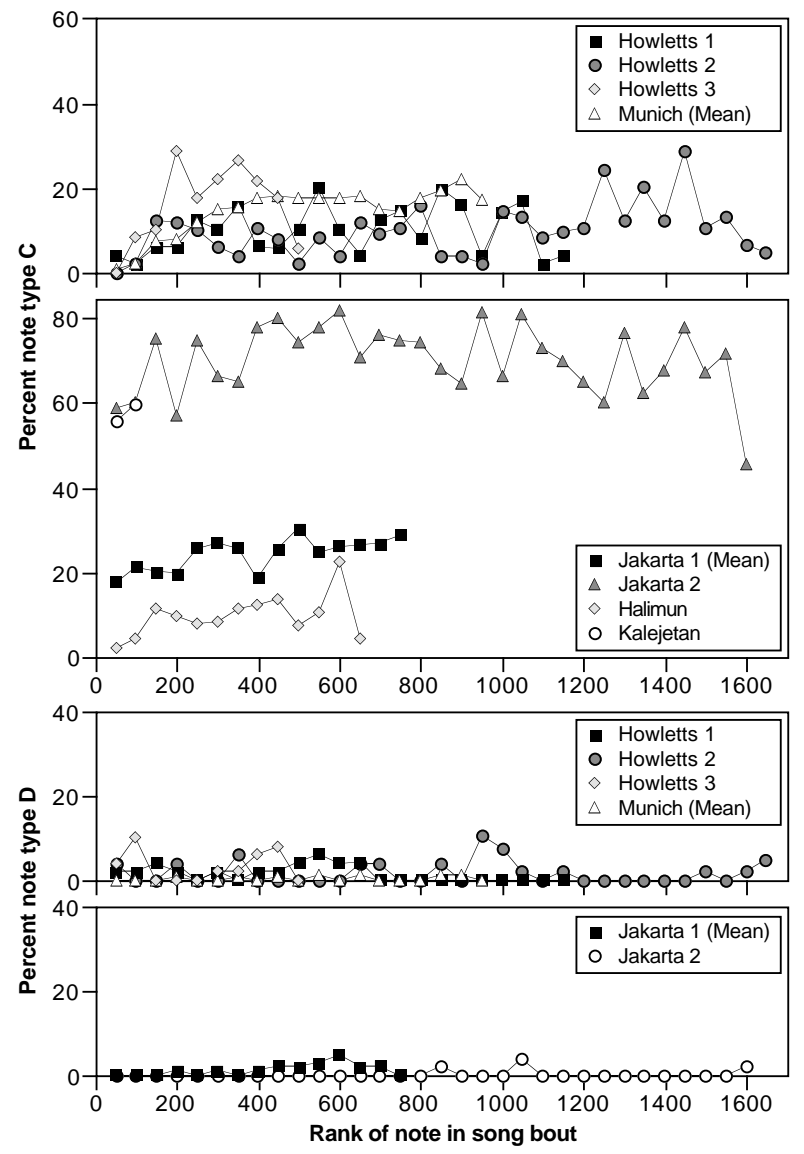

Fig. 3. (ctd.)

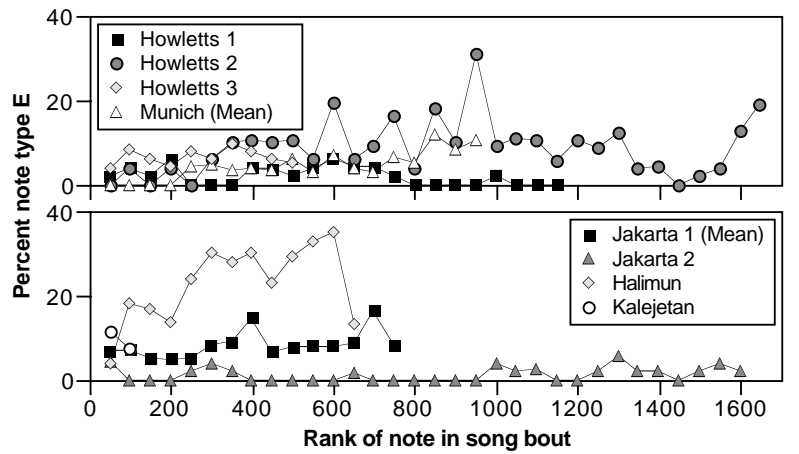

Fig. 3. (ctd.)

ally introduced, and after about 400 notes, the proportions of note types appears to stabilise somewhat. We use the term main phase for this part of the song bout. During the main phase, the dominant note types are B3 notes (25-50\%) in 3 males (Halimun, Howletts 1 and 2), B2 notes (30$50 \%$ ) in 3 males (Howletts 3, Jakarta 1, Munich), and $\mathrm{C}$ notes $(60-70 \%)$ in two males (Jakarta 2, Kalejetan). The changes in the note repertoire are summarised in Figure 4. 
Table 4. Comparison between the note type proportions in the song bouts of the study males. Stars indicate significant differences.

\begin{tabular}{|c|c|c|c|c|c|c|c|c|c|}
\hline \multirow{2}{*}{$\begin{array}{l}\text { Note } \\
\text { type }\end{array}$} & \multicolumn{7}{|c|}{ Number of notes produced by each individual (a-g) } & \multirow{2}{*}{$\begin{array}{l}\text { ANOVA } \\
p\end{array}$} & \multirow{2}{*}{$\begin{array}{l}\text { Scheffé post-hoc test } \\
\text { significant male } \\
\text { comparisons }\end{array}$} \\
\hline & $\begin{array}{l}\text { a } \\
\text { (Hali- } \\
\text { mun })^{1}\end{array}$ & $\begin{array}{l}\text { b } \\
\text { (How- } \\
\text { letts 1) }\end{array}$ & $\begin{array}{l}\text { c } \\
\text { (How- } \\
\text { letts 2) }\end{array}$ & $\begin{array}{l}\text { d } \\
\text { (How- } \\
\text { letts 3) }\end{array}$ & $\begin{array}{l}\text { e } \\
(\text { Jakarta } \\
1)^{1,2}\end{array}$ & $\begin{array}{l}\mathrm{f} \\
\text { (Jakarta } \\
2)^{1}\end{array}$ & $\begin{array}{l}\mathrm{g} \\
(\mathrm{Mu}- \\
\text { nich })^{3}\end{array}$ & & \\
\hline \multicolumn{10}{|c|}{ (a) Introductory phase: } \\
\hline \multicolumn{2}{|l|}{$\begin{array}{l}\mathrm{A}+ \\
\mathrm{B} 1\end{array}$} & 152 & 292 & 66 & & & 307 & $<0.0001 *$ & $\mathrm{bc}, \mathrm{cd}, \mathrm{cg}$ \\
\hline \multicolumn{2}{|l|}{ B2 } & 146 & 3 & 139 & & & 512 & $<0.0001 *$ & bc, cd, cg \\
\hline \multicolumn{2}{|l|}{ B3 } & 48 & 0 & 77 & & & 172 & $0.023 *$ & $\mathrm{~cd}$ \\
\hline \multicolumn{2}{|l|}{ B4 } & 6 & 31 & 19 & & & 79 & 0.093 & \\
\hline \multicolumn{2}{|l|}{$\mathrm{C} 1$} & 8 & 17 & 23 & & & 19 & $0.003 *$ & $\mathrm{dg}$ \\
\hline \multicolumn{2}{|l|}{$\mathrm{C} 2$} & 0 & 9 & 8 & & & 46 & $0.003 *$ & bg \\
\hline \multicolumn{2}{|l|}{ C3 } & 8 & 0 & 5 & & & 21 & 0.268 & \\
\hline \multicolumn{2}{|l|}{$\mathrm{C} 4$} & 3 & 0 & 7 & & & 16 & 0.275 & \\
\hline \multicolumn{2}{|l|}{ C5 } & 7 & 0 & 0 & & & 0 & 0.172 & \\
\hline \multicolumn{2}{|l|}{ C6 } & 0 & 0 & 0 & & & 7 & 0.338 & \\
\hline \multicolumn{2}{|l|}{ C7 } & 5 & 3 & 18 & & & 9 & $0.01 *$ & $\mathrm{dg}$ \\
\hline \multicolumn{2}{|l|}{ D } & 7 & 7 & 12 & & & 2 & $0.003 *$ & $\mathrm{dg}$ \\
\hline \multicolumn{2}{|l|}{$\mathrm{E}$} & 9 & 17 & 27 & & & 25 & $0.004 *$ & \\
\hline \multicolumn{2}{|l|}{$V^{4}$} & 5 & 0 & 0 & & & 2 & $0.002 *$ & $\mathrm{bc}, \mathrm{bd}, \mathrm{bg}$ \\
\hline \multicolumn{2}{|c|}{ Total } & 404 & 379 & 401 & & & 1217 & & \\
\hline \multicolumn{10}{|c|}{ (b) Main phase: } \\
\hline \multicolumn{2}{|l|}{$A+$} & \multicolumn{3}{|c|}{ B1 } & 156 & 249 & 31 & $<0.0001 *$ & $a b, c e, c g, f g$ \\
\hline B2 & 190 & 177 & 115 & 34 & 725 & 115 & 371 & $<0.0001 *$ & $\begin{array}{l}\text { ab, ae, af, bc, be, bf, } \\
\text { cd, ce, cg, ef, eg, fg }\end{array}$ \\
\hline B3 & 199 & 362 & 320 & 14 & 49 & 57 & 365 & $<0.0001 *$ & $\begin{array}{l}\text { ab, ae, af, bc, be, bf, } \\
\text { bg, ce, cf, eg, fg }\end{array}$ \\
\hline B4 & 119 & 8 & 63 & 2 & 4 & 0 & 111 & $<0.0001 *$ & $\begin{array}{l}\text { ab, ac, ad, ae, af, ag, } \\
\text { bg, eg, fg }\end{array}$ \\
\hline $\mathrm{C} 1$ & 4 & 28 & 10 & 3 & 23 & 113 & 16 & $<0.0001 *$ & af, cf, ef, fg \\
\hline $\mathrm{C} 2$ & 15 & 10 & 17 & 3 & 57 & 250 & 31 & $<0.0001 *$ & af, bf, cf, df, ef, fg \\
\hline $\mathrm{C} 3$ & 15 & 4 & 13 & 2 & 102 & 334 & 78 & $<0.0001 *$ & $\begin{array}{l}\text { af, be, bf, bg, ce, cf, } \\
\mathrm{cg}, \mathrm{df}, \mathrm{ef}, \mathrm{fg}\end{array}$ \\
\hline $\mathrm{C} 4$ & 3 & 13 & 2 & 0 & 27 & 2 & 28 & $<0.0001 *$ & $\mathrm{ce}, \mathrm{cg}$, ef, fg \\
\hline $\mathrm{C} 5$ & 2 & 17 & 0 & 0 & 1 & 238 & 0 & $<0.0001 *$ & af, bf, cf, df, ef, fg \\
\hline C6 & 11 & 0 & 42 & 0 & 85 & 35 & 24 & $<0.0001 *$ & ae, be, ef, eg \\
\hline $\mathrm{C} 7$ & 4 & 9 & 48 & 3 & 46 & 138 & 21 & $<0.0001 *$ & af, bf, cf, ef, fg \\
\hline $\mathrm{D}$ & 0 & 10 & 21 & 4 & 18 & 4 & 5 & $0.003 *$ & \\
\hline $\mathrm{E}$ & 145 & 14 & 124 & 5 & 112 & 21 & 70 & $<0.0001 *$ & $\begin{array}{l}\text { ab, ac, ad, ae, af, ag, } \\
\text { bc, be, cf, ef }\end{array}$ \\
\hline $\mathrm{V}^{4}$ & 0 & 3 & 38 & 0 & 19 & 115 & 2 & $<0.0001 *$ & $\begin{array}{l}\text { ab, af, bf, cf, cg, df, } \\
\text { ef, eg }\end{array}$ \\
\hline Total & 759 & 752 & 1112 & 85 & 1424 & 1671 & 1153 & & \\
\hline $\begin{array}{ll}1 & \mathrm{In} \\
2 & \mathrm{~T} \\
3 & \mathrm{Tl} \\
4 & \mathrm{~V}\end{array}$ & $\begin{array}{l}\text { uctory } \\
\text { ong bc } \\
\text { song } \\
\text { le fig }\end{array}$ & $\begin{array}{l}\text { e not re } \\
\text { nalysed } \\
\text { analyse }\end{array}$ & ed on & & & & & & \\
\hline
\end{tabular}

We used song note number 400 (excluding inspiration notes from the count) as an arbitrary demarcation point between the introductory phase and the main phase of the song bout, and we compared the frequency of note types (and the variable figure) in each phase between the individuals using ANOVA (Table 4). In the introductory phase, the frequencies of 9 out of 14 note types significantly differ among the study males, in the main phase, all 14 note types tested differ significantly. The higher number of significant differences in the main phase song pro- bably results from the larger number of notes available for comparison from this part of the song bout. In the introductory phase, most significant pairwise comparisons (Scheffé's post-hoc tests) include the Munich male. The sample size was much larger for this male than for the others, because three complete song bouts were available instead of only one. This supports the conclusion that the number of significant differences between individuals may largely be a question of sample size. 


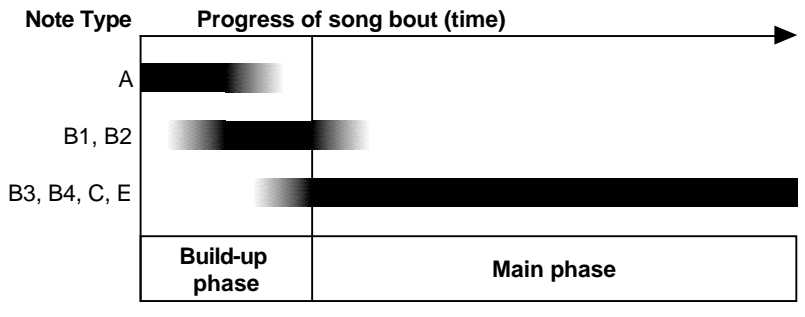

Fig. 4. Diagram of the changes in the note repertoire used during various phases of the song bout of male silvery gibbons.

\section{Inter-phrase interval}

The male songs of $H$. moloch appear to be highly variable. We found virtually no stereotypic repeated structures comparable to the so-called great call phrases of the female songs (Dallmann and Geissmann, 2001a, b). This impedes the recognition of phrases (i.e. of elements which are typically uttered in recognisable sequences). Because the note intervals within phrases are, by definition, shorter than those between phrases, it should be possible to identify a critical interval duration which discriminates particularly well between inter-phrase and intra-phrase intervals. For this purpose, we determined the frequency distribution of note interval durations in steps of $0.02 \mathrm{~s}$ for the songs of each male. We expected that both inter-phrase intervals and intra-phrase intervals would both occur more frequently than intermediate note intervals. The latter should be recognisable as a trough in the frequency distribution curve and represent a suitable critical interval duration distinguishing between inter-phrase intervals and intra-phrase intervals.

Each song appears to exhibit several local minima in the frequency distribution of the note intervals. Most minima occur in some individuals only, but not in others. A through near $0.75 \mathrm{~s}$ consistently occurred in the frequency distribution of all study animals, however. Therefore, we defined $0.75 \mathrm{~s}$ as the critical interval. In the following analysis, notes separated by an interval of more than $0.75 \mathrm{~s}$ are considered as belonging to different phrases. Likewise, non-phrase notes (i.e. single notes) must be isolated from all other notes by intervals of more than $0.75 \mathrm{~s}$.

\section{Song motivation}

Song motivation (i.e. the gibbon's drive to sing) cannot be measured directly. As an estimate for

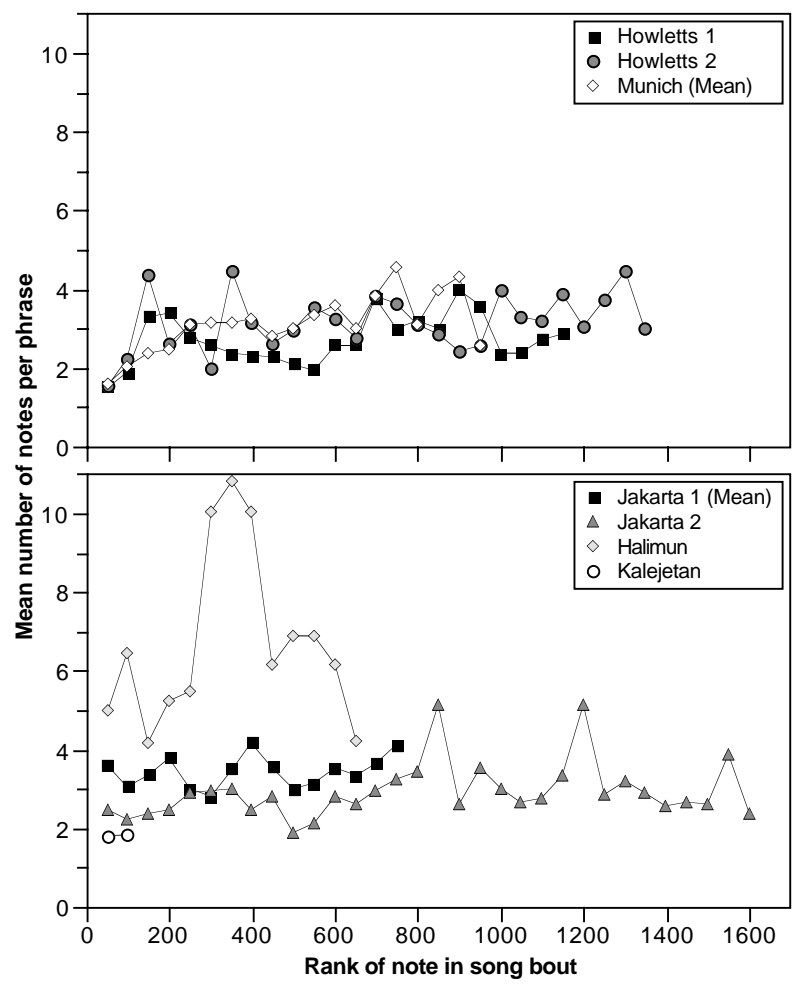

Fig. 5. Song motivation (number of notes per phrase) in consecutive 50-note sections of the male song bouts of Hylobates moloch. The Halimun, Jakarta 1, Jakarta 2 and Kalejetan males are plotted separately, because the beginnings of their song bouts were not recorded on tape.

song motivation, we use the average number of notes per phrase, determined over consecutive song sections of 50 notes. Inspiration notes were ignored in this calculation.

In Figure 5, song motivation is shown as a function of song bout progression, as determined in groups of 50 consecutive notes. At the beginning of a song bout, the average number of notes per phrase is below a value of 1.7 notes (Figure 5, upper graph). In each case, song motivation increases early during the song bout (i.e. during about the first $200-250$ notes). During the main part of the song bout, song motivation may still exhibit considerable fluctuations, but tends to remain within a range of $2.5-4.0$ notes/phrase.

The beginning of the song bouts from Halimun, Jakarta 1, Jakarta 2 and Kalejetan (Figure 5, lower graph) was not recorded on tape. An initial increase in song motivation is not visible in these song bouts. The songs of the Jakarta 1 and 2 males exhibit a range of song motivation resembling the 
Table 5. Kendall rank-order correlations between note types and song motivation (defined as notes per phrase, see text). Each cell below row 4 includes the correlation coefficient (Tau) and the error probability $(p)$. Stars and bold print indicate significant correlations.

\begin{tabular}{|c|c|c|c|c|c|c|}
\hline \multirow{2}{*}{$\begin{array}{l}\text { Note } \\
\text { type }\end{array}$} & \multicolumn{6}{|l|}{ Individual $^{\mathrm{a}}$} \\
\hline & Howletts 1 & Howletts 2 & Munich & Halimun & Jakarta 1 & Jakarta 2 \\
\hline \multirow{3}{*}{$\begin{array}{l}\text { Number of } \\
\text { notes }{ }^{b}\end{array}$} & 1159 & 1657 & 483 & 615 & 658 & 1667 \\
\hline & & & 935 & & 766 & \\
\hline & & & 950 & & & \\
\hline \multirow{3}{*}{$\begin{array}{l}\text { Number of } \\
\text { phrases }{ }^{b}\end{array}$} & $295(453)$ & $379(546)$ & $106(178)$ & $81(98)$ & $143(222)$ & $373(592)$ \\
\hline & & & $205(301)$ & & 139 (195) & \\
\hline & & & $190(341)$ & & & \\
\hline \multirow[t]{2}{*}{$\mathrm{A}+\mathrm{B} 1$} & -0.263 & -0.372 & -0.673 & -0.286 & 0.163 & -0.016 \\
\hline & 0.078 & $0.002 *$ & $<0.0001 *$ & 0.174 & 0.396 & 0.896 \\
\hline \multirow[t]{2}{*}{ B2 } & -0.188 & 0.128 & -0.288 & -0.219 & -0.240 & 0.138 \\
\hline & 0.209 & 0.293 & 0.085 & 0.297 & 0.212 & 0.266 \\
\hline \multirow[t]{2}{*}{ B3 } & 0.292 & 0.259 & 0.594 & 0.245 & 0.000 & 0.203 \\
\hline & 0.051 & $0.034 *$ & $0.0004 *$ & 0.243 & $>0.999$ & 0.103 \\
\hline \multirow[t]{2}{*}{ B4 } & 0.100 & 0.028 & 0.295 & 0.116 & 0.267 & does not occur \\
\hline & 0.506 & 0.818 & 0.078 & 0.581 & 0.165 & \\
\hline \multirow[t]{2}{*}{$\mathrm{C} 1$} & -0.278 & -0.069 & -0.007 & -0.404 & 0.000 & -0.200 \\
\hline & 0.063 & 0.572 & 0.965 & 0.055 & $>0.999$ & 0.108 \\
\hline \multirow[t]{2}{*}{$\mathrm{C} 2$} & 0.058 & 0.266 & 0.129 & -0.041 & 0.368 & 0.352 \\
\hline & 0.698 & $0.029 *$ & 0.442 & 0.844 & 0.080 & $0.047 *$ \\
\hline \multirow[t]{2}{*}{$\mathrm{C} 3$} & 0.230 & 0.166 & 0.341 & 0.053 & -0.116 & -0.231 \\
\hline & 0.124 & 0.175 & $0.041 *$ & 0.802 & 0.581 & 0.063 \\
\hline \multirow[t]{2}{*}{$\mathrm{C} 4$} & 0.184 & -0.104 & 0.318 & 0.258 & 0.470 & 0.012 \\
\hline & 0.219 & 0.393 & 0.057 & 0.220 & $0.025 *$ & 0.926 \\
\hline \multirow[t]{2}{*}{$\mathrm{C} 5$} & 0.341 & does not occur & does not occur & 0.048 & 0.000 & -0.016 \\
\hline & $0.023 *$ & & & 0.821 & $>0.999$ & 0.896 \\
\hline \multirow[t]{2}{*}{ C6 } & does not occur & 0.276 & 0.013 & 0.151 & 0.275 & -0.086 \\
\hline & & $\mathbf{0 . 0 2 4} *$ & 0.937 & 0.473 & 0.191 & 0.488 \\
\hline \multirow[t]{2}{*}{$\mathrm{C} 7$} & -0.122 & 0.325 & 0.052 & 0.264 & -0.325 & 0.140 \\
\hline & 0.416 & $0.008 *$ & 0.755 & 0.209 & 0.122 & 0.261 \\
\hline \multirow[t]{2}{*}{$\mathrm{C}$, combined } & 0.060 & 0.387 & 0.382 & 0.208 & -0.249 & 0.091 \\
\hline & 0.687 & $0.002 *$ & $0.022 *$ & 0.323 & 0.196 & 0.463 \\
\hline \multirow[t]{2}{*}{$\mathrm{D}$} & -0.360 & -0.133 & 0.109 & does not occur & -0.062 & 0.005 \\
\hline & $0.016 *$ & 0.275 & 0.515 & & 0.746 & 0.970 \\
\hline \multirow[t]{2}{*}{$\mathrm{E}$} & -0.173 & -0.027 & 0.401 & 0.478 & 0.153 & 0.124 \\
\hline & 0.247 & 0.825 & $0.016 *$ & $0.022 *$ & 0.426 & 0.319 \\
\hline
\end{tabular}

a Kalejetan was excluded because the tape-recorded song fragment was to short to calculate a correlation (108 notes, 24 phrases if single notes are excluded, 48 phrases if single notes are included).

More than one song was analysed for the Munich and Jakarta 1 males, respectively; the number of phrases and number of notes are listed for each song separately. The number of phrases excludes single notes (i.e. phrases with just one note), the value in parentheses includes them.

main part of the complete song bouts described above (i.e. 2.5-4.0 notes/phrase). Song motivation in the Kalejetan male is low (around 1.8 notes per phrase), suggesting that the available part of the song bout represents an initial section, but the fragment is too short to draw reliable conclusions. The song bout of the Halimun male, however, exhibits unusually high values, mostly in the range of 4.0-7.0 notes/phrase, and reaching peak levels of $10-11$ notes/phrase.

The frequency of several note types correlates with song motivation. A total of 16 significant correlations were found $(p<0.05)$, and 3 additional correlations are close to significance $(p<$ $0.06)$. These correlations are summarised in Table 5. The numbers of significant correlations differ among the males. This difference appears to be related neither to the number of notes nor to the number of phrases that were analysed of each male (Table 5). Instead, more significant correlations were found in the complete songs of the Howletts 1, Howletts 2 and Munich males (2, 6 
and 5 correlations, respectively) than in the incompletely recorded songs of the Halimun, Jakarta 1 and Jakarta 2 males (1 significant correlation each).

As shown in Table 5, no two males have exactly the same note types among their set of significant correlations. Only five note types exhibit matching correlations in two males (i.e. $\mathrm{A}+\mathrm{B} 1, \mathrm{~B} 3, \mathrm{C} 2, \mathrm{C}$ combined, E), six note types are significant in only one male $(\mathrm{C} 3, \mathrm{C} 4, \mathrm{C} 5, \mathrm{C} 6, \mathrm{C} 7$, D) and three note types (B2, B4, C1) do not exhibit any correlation with song motivation.

\section{Phrase composition}

Typical excerpts of the main phase of each study animal are shown in the sonagrams of Figure 6. The males appear to differ strongly not only in the proportions of the various note types, but also in the structure of the phrases.

In order to understand the sequential structure of note types in male phrases, we compared all phrases from the main song phase among all available song bouts as well as among individuals. Only phrases of at least 3 notes were included, and inspiration notes were ignored for this part of the

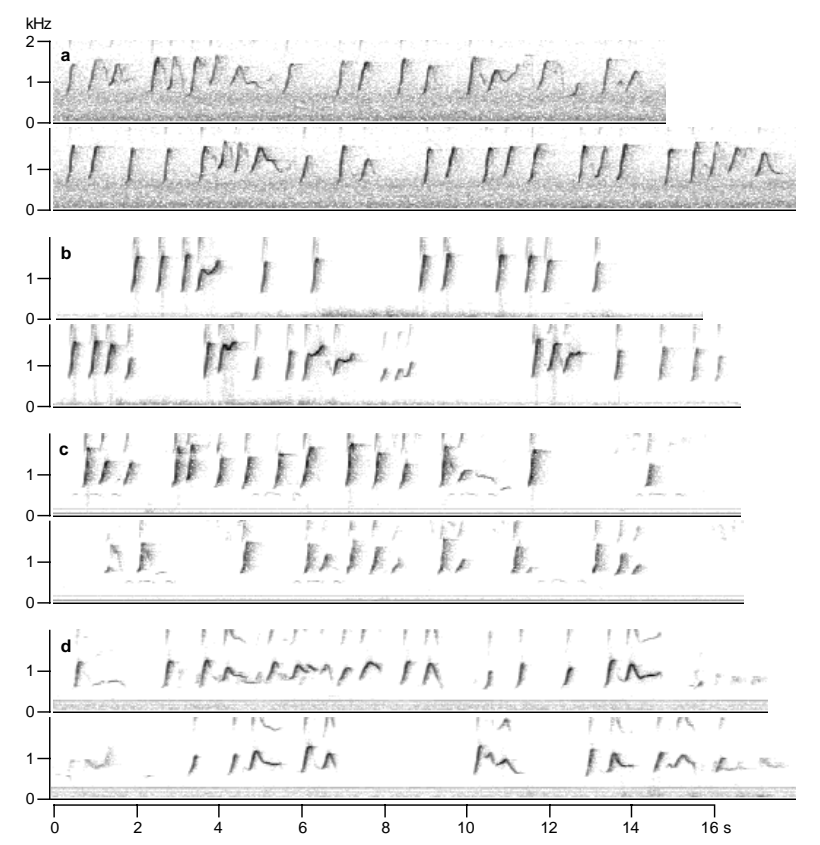

Fig. 6. Representative excerpts from song bouts of silvery gibbon males, showing individual differences and low degree of stereotypy in song structure. All sonagrams stem from the main phase of song bouts. The individual males are: (a) Halimun, (b) Howletts 1, (c) Howletts 2, (d) Jakarta 1, (e) Jakarta 2, (f) Kalejetan, (g) Munich. analysis. The calculated note sequence probabilities for each gibbon are shown in Figure 7. Data from multiple song bouts of the same individual were pooled.

The Halimun male (Fig. 7a) begins $52 \%$ of his phrases in the main song phase with a note of the type B2. This note is followed by a B3 note in $42 \%$ of the cases, which is followed by two more notes of the same type in succession. All other note sequences also occurring in this male's phrases only play a subordinate role.

Male 1 from Howletts (Fig. 7b) begins $83 \%$ of his phrases with a note of the type B3. This note is followed by a B3 note in $63 \%$ of the cases, which is followed, again, by two more notes of the same type in succession. Male 2 from Howletts (Fig. 7c) exhibits the same preferred phrase structure, but the relative frequencies for each position in the phrase are less narrowly determined.

The tape-recorded song bouts of the Jakarta 1 male (Fig. 7d) reveal a much different preferred order of phrase notes. The first note is of the B2 note type in $59 \%$ of the cases, similar to the Halimun male. Unlike the phrases of any other study male, the first note is followed by a note of type B2 in $49 \%$ of all phrases (or - in $43 \%$ - by note type $\mathrm{C}$ ), followed by $\mathrm{C}$ and $\mathrm{B} 3$ in third and fourth positions, respectively.

The Jakarta 2 male (Fig. 7e) starts $78 \%$ of all phrases with note type $\mathrm{C}$ and preferentially inserts type $\mathrm{C}$ in positions 2-5 of his phrases as well. This gibbon exhibits the most pronounced preference for note type $\mathrm{C}$ of all study males. Moreover, the phrase structure of this male appears to be the least variable of the study males and, therefore,

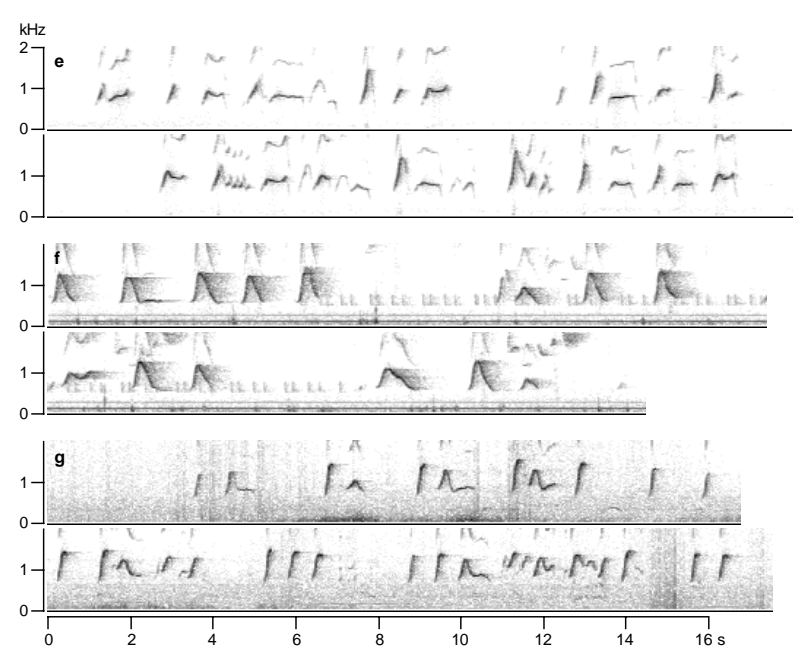

Fig. 6. (ctd.) 

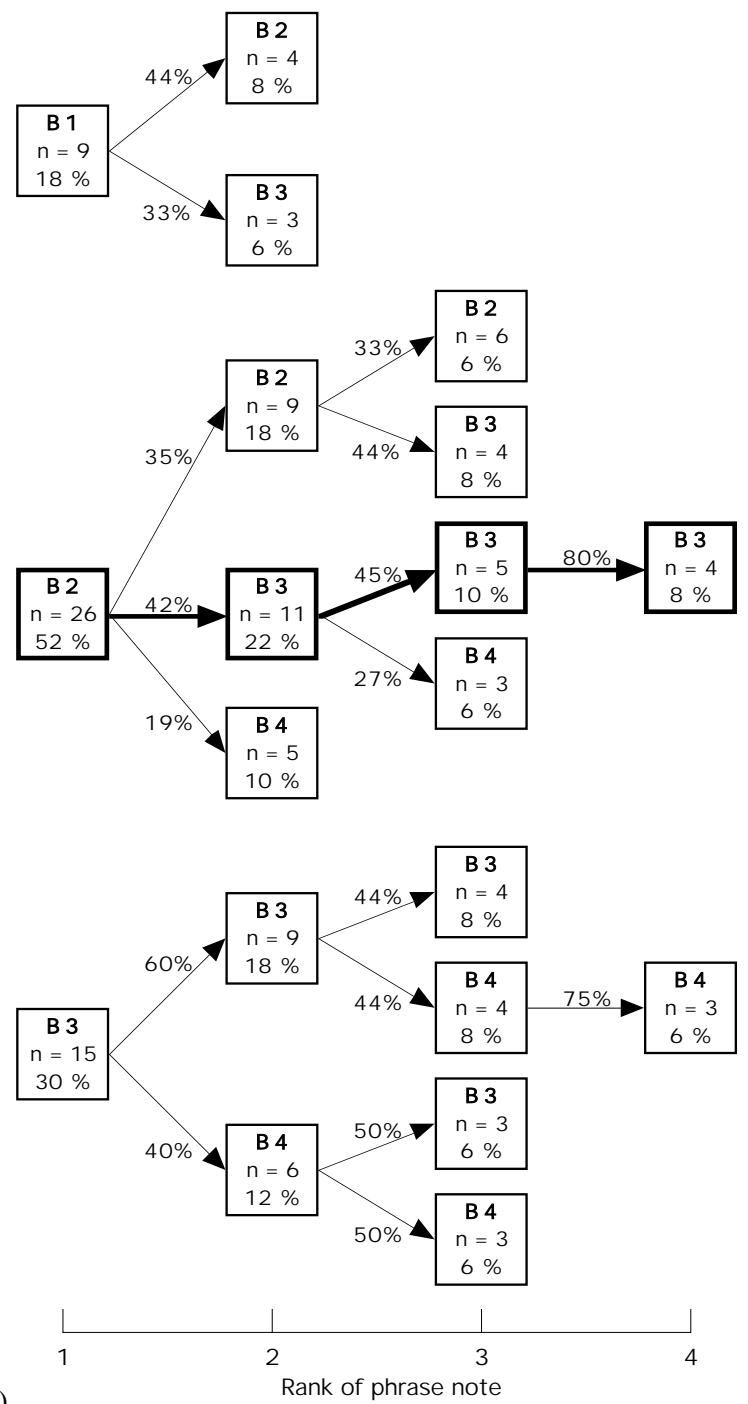

(b)
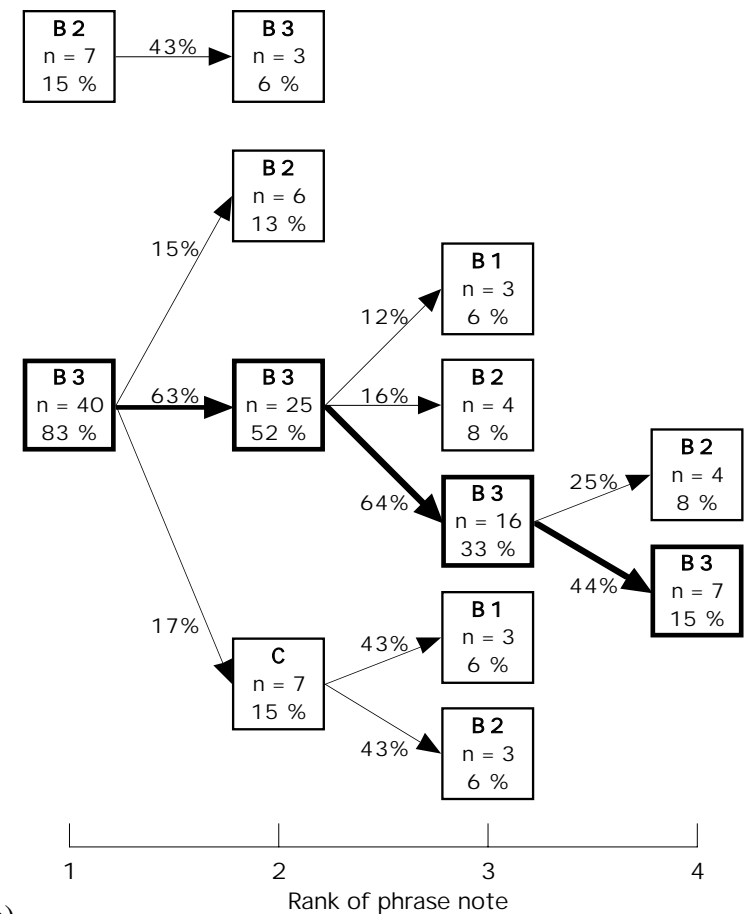

Fig. 7. (ctd.)

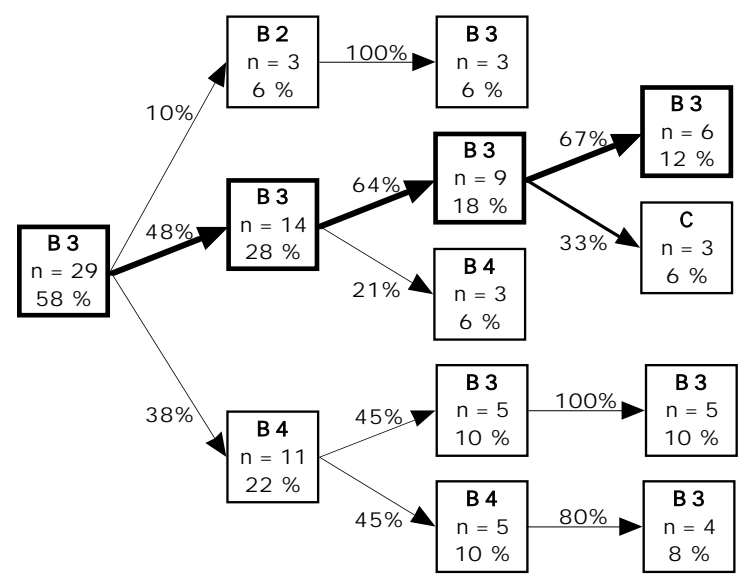

Fig. 7. Phrase structure in the male song of Hylobates moloch: (a) Halimun, (b) Howletts 1, (c) Howletts 2, (d) Jakarta 1, (e) Jakarta 2, and (f) Munich. Data of several song bouts of the same individual (Munich, Jakarta 1) were pooled. Fifty phrases were analysed of each song (including only phrases with at least three notes). The preferred phrase structure is drawn in bold lines. The letters in the boxes indicate the note type. The numbers in the boxes indicate the absolute (n) and the relative frequency (\%) of a note type occurring in this particular position in the phrase, and the numbers accompanying the arrows represent the relative frequency of two particular note types following each other in these particular positions (ranks) within a phrase. In order to keep the figures simple, we omitted relative frequencies below $5 \%$ and absolute frequencies below $n=2$.

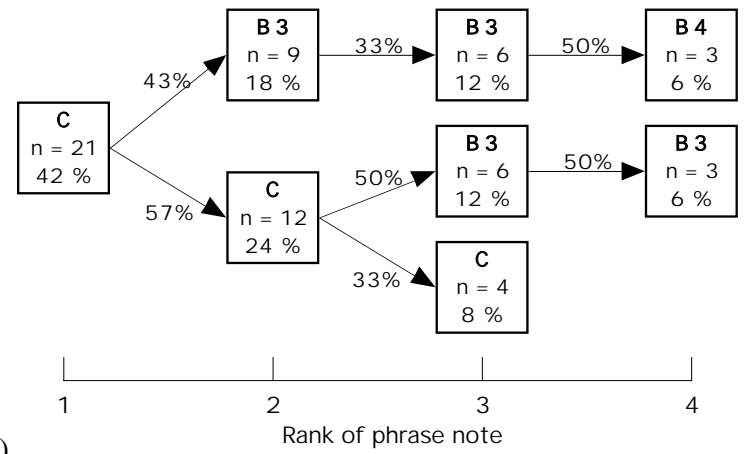

Fig. 7. (ctd.) 

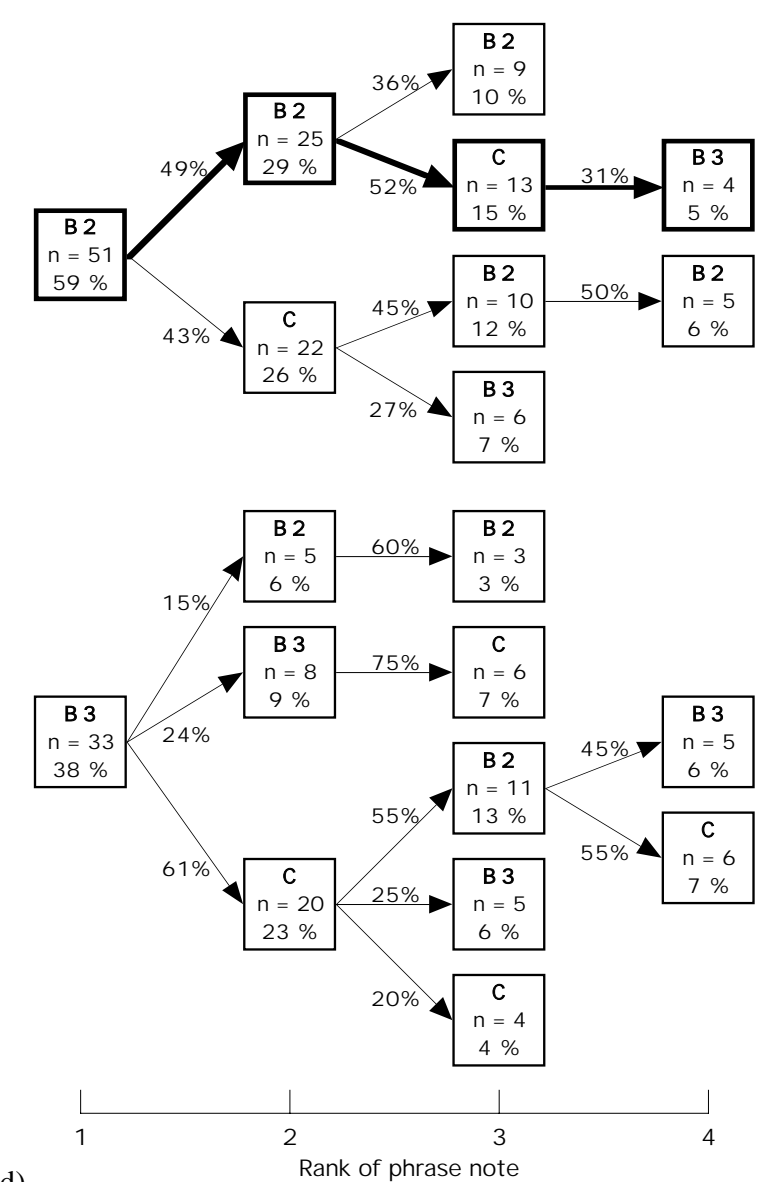

(d)

Fig. 7. (ctd.)

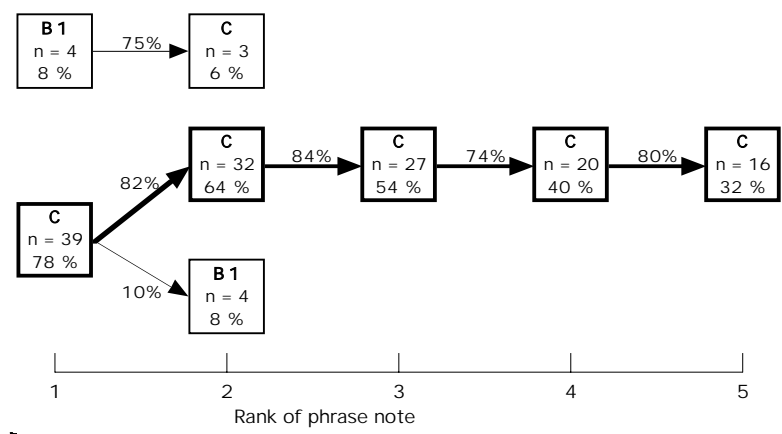

(e)

Fig. 7. (ctd.)

exhibits the highest transition probabilities between successive notes.

The Kalejetan male was not included in this analysis because the shortness of the taperecorded song fragment precluded the calculation of reliable transition probabilities. The high proportion of type $\mathrm{C}$ notes in the available song fragment (as described above, see Figure 3) suggests, however, that this male's phrase structure may resemble that of the Jakarta 2 male.

Similar to the Howletts 1 and 2 males, $75 \%$ of

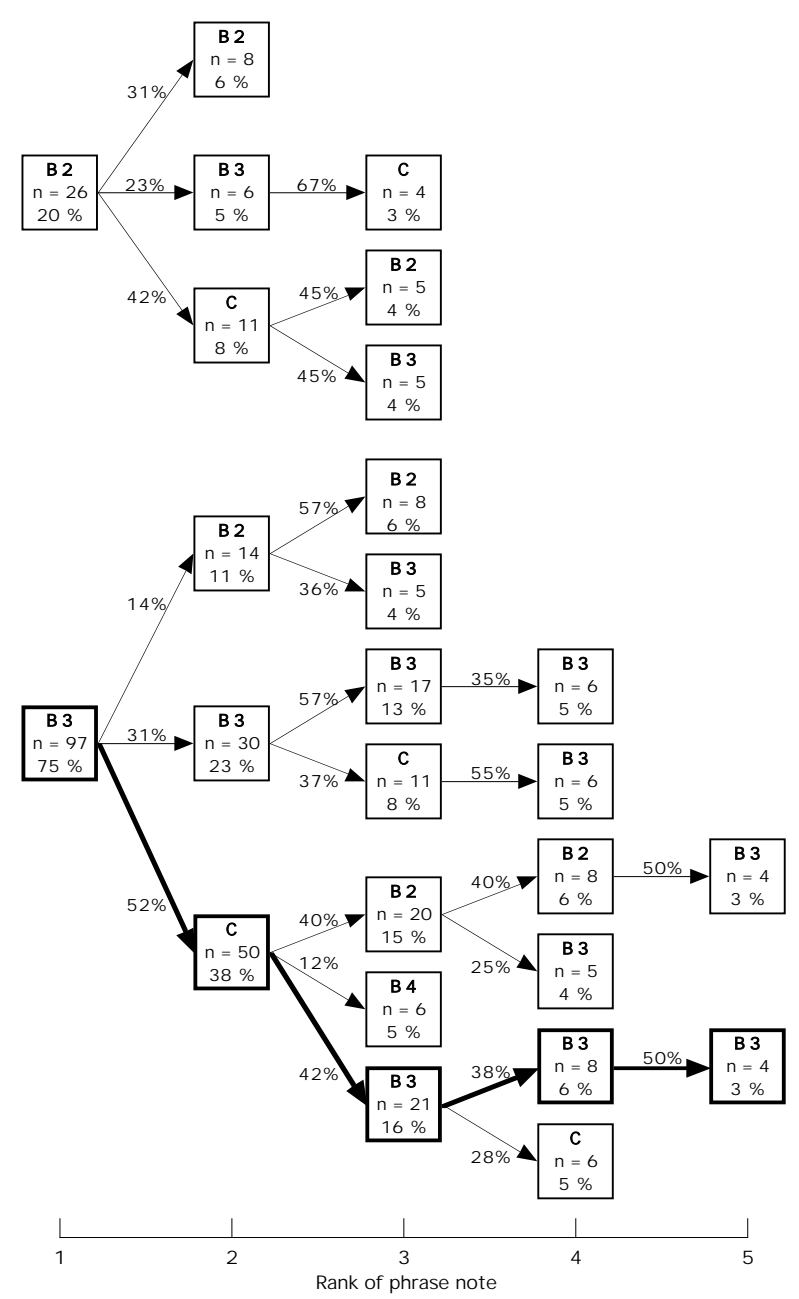

(f)

Fig. 7. (ctd.)

all phrases of the Munich male (Fig. 7f) begin with a note of type B3. In contrast to other males, a $\mathrm{C}$ note follows on the second position (52\%). Notes three, four and five of the phrases are mostly of type B3.

The preferred note sequences in the phrases of each male are summarised in Table 6 . In addition, the table also separately lists the results for multiple songs of the Jakarta 1 and Munich males. As can be seen in the list, the first note of the phrase remains of the same note type in all song bouts of the same male, but the phrase structure of neither male is completely stable. At least in the Munich male, the differences in phrase structure are relatively moderate, considering that the third tape-recording (Munich 1c) was made 8 years after the first one (Munich 1a).

The proportions of the most common note sequences (one of each male) occurring in song phrases were compared among individual gibbons using minimum discrimination information statistics, revealing a strongly significant difference among the males $(2 I=114.7, \mathrm{df}=25, \mathrm{p}<0.001)$. 
Table 6. The most frequently used order of note types in song phrases of each tape-recorded song bout.

\begin{tabular}{|c|c|c|c|c|c|}
\hline Tape-recording & 1. note of phrase & 2. note of phrase & 3. note of phrase & 4. note of phrase & 5. note of phrase \\
\hline Halimun & B2 & B3 & B3 & B3 & - \\
\hline Howletts 1 & B3 & B3 & B3 & B3 & - \\
\hline Howletts 2 & B3 & B3 & B3 & B3 & - \\
\hline Jakarta 1a & B2 & $\mathrm{C}$ & B3 & - & - \\
\hline Jakarta 1b & B2 & B2 & $\mathrm{C}$ & B3 & - \\
\hline Jakarta 1 total & B2 & $\mathrm{B} 2$ & $\mathrm{C}$ & B3 & - \\
\hline Jakarta 2 & $\mathrm{C}$ & $\mathrm{C}$ & $\mathrm{C}$ & $\mathrm{C}$ & $\mathrm{C}$ \\
\hline Munich 1a & B3 & $\mathrm{C}$ & B3 & $\mathrm{C}$ & - \\
\hline Munich 1b & B3 & $\mathrm{C}$ & B2 & B2 & - \\
\hline Munich 1c & B3 & B3 or $\mathrm{C}$ & B3 & B3 & - \\
\hline Munich total & B3 & $\mathrm{C}$ & B3 & B3 & B3 \\
\hline
\end{tabular}

\section{Discussion}

\section{Male note repertoire}

Our study revealed that the note repertoire of silvery gibbon males appears to be much more complex than previously thought. The three note types defined by Kappeler (1984 a) are not sufficient to describe their vocal diversity. We grouped the male note repertoire of $\mathrm{H}$. moloch in two classes (expiration and inspiration notes). The expiration notes are further divided into four groups (labelled A through E), which are further divided into distinct note types, resulting in a total of 14 note types.

Even this much larger number represents a conservative approach which cannot fully describe to the vocal variability of the male songs of this gibbon species. Especially the variable and inspiration notes (types D and E) could easily be split into a larger number of distinct variants. Because these note types occur only rarely in the songs that we analysed, a further subdivision would probably not have revealed additional insights in the song syntax.

$W a$ notes (type B) are the dominant song notes in most males of this study. Similar wa notes are also produced by other species of the genus Hylobates - such as H. lar (Raemaekers et al., 1984), H. muelleri and H. agilis (Haimoff, 1983) and usually represent the most common note type in the repertoire of these species (Geissmann, own observation). The wa notes appear to be so typical of the genus Hylobates (least of all $H$. pileatus) that this group might also be named the "wa note gibbons".

\section{Composition of the song bout}

Despite their variability, male songs appear to follow certain syntactical rules. Song bouts typically begin softly with several single oo notes (type A), which gradually develop into single $w a$ notes (mostly type B1). The first phrases occurring in the song bout are short and simple, consisting of wa notes only. As the song bout continues, phrases become longer and more note types are included. This gradual development from simple oo notes to complex phrases can be seen in the completely sonagraphed (but unusually short) song bout in Appendix 1. The progressive elaboration appears to be typical of male solo songs of most (possibly all) gibbon species (e.g. Demars and Goustard, 1978; Goustard, 1976; Haimoff, 1984b, 1985; Mitani, 1988; Raemaekers et al., 1984; Tenaza, 1976; Whitten, 1982).

Especially in the $w a$ notes, a fine division into note types is important: Whereas most wa notes at the beginning of the song bout exhibit a small range of frequency modulation (note type B1), the range of most $w a$ notes during the main song phase is more than twice as large (type B3).

\section{Phrase syntax}

It is difficult to identify a clearly preferred number of notes per phrase - here termed song motivation - in a song bout. In the introductory phase, the average number of notes per phrase is usually short and below 2 notes / phrase (single note phrases are included in this count, but inspiration notes are not). The average phrase length in 
the main song phase is longer and amounts to 2 notes/phrase. This value may increase, however, to averages of up to 5 notes / phrase in some parts of the song or in some individuals.

The number of notes per phrase most strongly increases early in the song bout (i.e. during the first 150-400 notes). The initial increase in song motivation may not be steady, and non-regular fluctuations of song motivation can occur throughout the whole song bout.

The frequency of some note types are significantly correlated with song motivation, but none of these correlations are consistent across our study males (see Table 5), again suggesting individual preferrences.

Some of the song bouts we studied were not completely tape-recorded. As none of them exhibits the increase of motivation, which is typical of the introductory phase, the introductory phase of the song bout was apparently missed when the recording was carried out. This probably explains why we found fewer significant correlations between note types and song motivation in these song bouts. Obviously, incomplete song bouts should not be used when calculating this type of correlation.

Because of the high variability within male songs of $H$. moloch, it is difficult to recognise recurrent patterns. In contrast to the female great calls, males produce much less stereotyped song phrases. Yet, all study animals appear to use individually-preferred note sequences in the main song phase (see Table 6). The Halimun male, for instance, prefers the note sequence B2 B3 B3 B3 in his phrases. The Munich male, on the other hand, prefers $\mathrm{B} 3 \mathrm{CB} 3 \mathrm{~B} 3 \mathrm{~B} 3$, and the Jakarta male 2 prefers $\mathrm{C} \mathrm{C} \mathrm{C} \mathrm{C} \mathrm{C.}$

\section{Individuality}

Songs of individual males differ significantly among each other in the note types they use and in how often they use them, both during the introductory phase and the main phase of their song bouts. Differences are particularly common in the different types of chevron notes (type C). In addition, all study animals appear to exhibit individual preferrences for note sequences in the main song phase.

Our evidence for individuality should be regarded with caution, however, because our samples consist of only one song bout for most study males. Therefore, the significant differences in note repertoire and phrase composition could have been influenced by differences in the behavioural context of the songs or the emotional state of the singers, although no such differences were obvious to us. To properly demonstrate individuality would require to find specific characteristics consistently occurring in several song bouts of each male. This appeared to be the case in the multiple song bouts we analysed of two of our study males ( 3 of the Munich male and 2 of the Jakarta 1 male).

\section{Comparison with male singing in other gibbons}

The frequency of singing varies between populations and may be influenced by variables, such as population density, availability of resources, sexual activity and weather. Yet, roughly, most gibbon species duet almost daily (Leighton, 1987), except siamangs which duet about one day in three (Gittins and Raemaekers, 1980). Among the non-duetting gibbon species, male Kloss's gibbons sing almost daily (Whitten, 1982), whereas most male silvery gibbons appear to sing only rarely, about once a week (Geissmann and Nijman, 2001). We cannot confirm Kappeler's (1984a) conclusion that mated males of $H$. moloch do not sing, because the Munich, Howletts 2 and Howletts 3 males of this study were mated. Yet, the silvery gibbon appears to be exceptional among all gibbon species because of the rarity of its male singing.

In all examined gibbon species (e.g. H. klossii, H. lar, N. leucogenys) male song bouts usually begin with simple, single notes. During the course of the song bout, additional, more complex note types are included and the phrases become longer and more complex (Schilling, 1984; Tenaza, 1976; Whitten, 1980, 1982; Raemaekers, Raemaekers and Haimoff, 1984). In this respect, the male song of $\mathrm{H}$. moloch corresponds to that of the other species.

Male songs of many gibbon species such as H. klossii (Tenaza, 1976; Whitten, 1980, 1982), all species of the genus Nomascus (Schilling, 1984, Geissmann, unpublished data) and Symphalangus syndactylus (Geissmann, unpublished data) produce relatively stereotyped phrases exhibiting a moderate variability both within and between individuals. Figure 8 shows several sonagrams documenting the repetitive structuring of the male song in H. klossii and N. leucogenys. Not only do individual males of these species repeat their phrases 


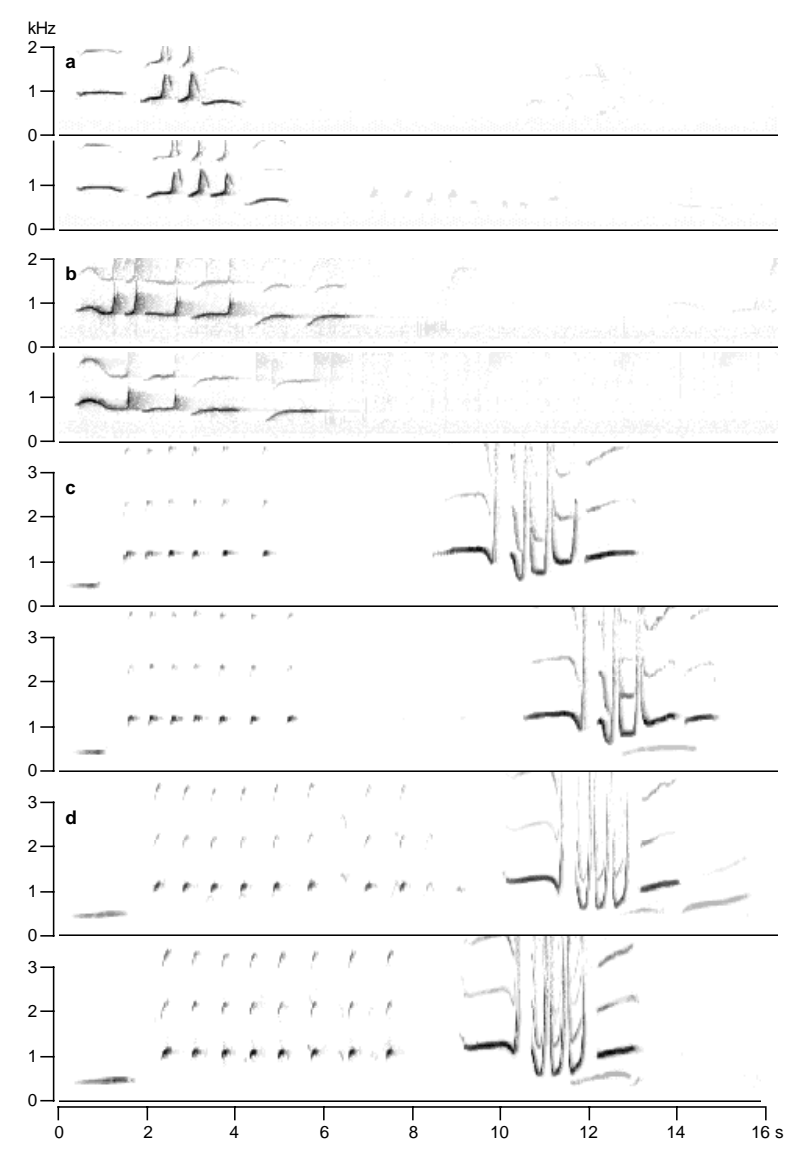

Fig. 8. Sonagrams documenting the relatively stereotyped song structure, both in intra- and inter-individual comparison, in males of Hylobates klossii and Nomascus leucogenys leucogenys, respectively. For each individual two consecutive phrases $(H$. klossii) or two consecutive phrase cycles $(N$. leucogenys) from the main phase of the song bout are shown. Intervals between lines have been cut in order to fit each sonagram on one line. (a) H. klossii, Twycross Zoo, 8 Oct. 1988; (b) H. klossii, Siberut, Mentawai, recorded 1973 by R.L. Tilson, published in Marshall and Marshall (1967); (c) N. leucogenys, Ménagerie du Jardin de Plantes, Paris, 17 May 1988; (d) N. leucogenys, Hannover Zoo, 8 July 1997.

in a relatively stereotyped way during the main phase of the song bout, but other males of the same species produce very similar phrases.

In contrast to the taxa mentioned above, male phrases of $H$. moloch appear to exhibit very few stereotyped structures and are characterised by a high degree of variability in their phrases. A relatively high degree of intra-individual variability may also occur in some other species of the genus Hylobates, as well. In a study on male songs of $H$. agilis, the authors concluded that male song phrases are extremely versatile. Precise copies of phrases are rarely repeated consecutively, and the repertoire of individual males is very large (Mitani, 1988; Mitani and Marler, 1989). In $H$. moloch, however, intra-individual variability in phrase structure appears to be more variable than what has previously been documented for gibbons. Although males may exhibit conspicuous recurrent structures (e.g. the trill figure in Jakarta male 2 or the sequence of a high wa note of type B3 followed by a very low note of type B1 in Howletts male 3), hardly two phrases are identi$\mathrm{cal}$, as demonstrated in the sonagrams of a complete song bout in the Appendix. The difference between the highly variable male phrases of H. moloch (Fig. 6) and the much more stereotypic male songs of other gibbons (Fig. 8) could hardly be more striking.

Moreover, the unusually high variability of silvery gibbon male songs occurs on two levels: within and between individuals. Songs of different silvery gibbon males may differ so much in their song structure as to build up their phrases from almost completely different note types (e.g. compare the phrase structure of Howletts male 1 and Jakarta male 2 in Fig. $7 b$ and e). This has not previously been observed in other gibbon species.

From a phylogenetic point of view, the highly variable male song of $H$. moloch appears to be a derived feature among gibbons. This is supported by two independent lines of evidence. First, a high degree of male song stereotypy is typical not only of $H$. klossii, but also of the genera Nomascus and Symphalangus, both of which have been found to occupy more basal positions in hylobatid phylogeny than the genus Hylobates (e.g. Geissmann, 2002b; Roos and Geissmann, 2001). The variability of the male song of the genus Bunopithecus has not been analysed in sufficient detail to be included in the comparison. Second, gibbon songs have been proposed to be homologous with loud calls typically produced by adult males of most species of catarrhine primates (Geissmann, 2000; Geissmann and Dallmann, 2002). Because loud calls of most species exhibit a high degree of stereotypy (Geissmann, unpublished observations), this provides further support for interpreting the highly variable male song of $\mathrm{H}$. moloch as a derived characteristic among the Hylobatidae.

\section{Possible functions of male singing}

The song is an important part of the gibbon behavioural repertoire. Various functions have been 
suggested for gibbon songs. The most commonly proposed functions include defence of resources (territories, mates), mate attraction, and strengthening and advertisement of pair bonds (Geissmann, 1993, 1995, 1999, 2000; Geissmann and Orgeldinger, 2000; Haimoff, 1984; Leighton, 1987).

If the song served to strengthen and/or advertise the pair bond, mated pairs should engage in duet singing. This is not the case in H. moloch (Kappeler, 1984 a, Geissmann and Nijman, 2001). Instead, the study males appeared to abort their song bouts each time when a female started to sing. This occurred not only in three of the song bouts that were analysed for this study, but also in at least three other male song bouts of captive silvery gibbons and in one male song monitored in Central Java (Geissmann, unpublished observations). Although male silvery gibbons may occasionally call together with females in "scream bouts" (Geissmann and Nijman, 2001) or "border conflict call bouts" (Kappeler, 1984 a), these calls have a different organisation and are not recognised as song bouts.

Traditionally, territorial defence is cited as one of the main functions of male gibbon songs, but other functions have been proposed, such as mate attraction, singing in order to defend mate and offspring against other males, and mediating spacing among individuals (Cowlishaw, 1992; Geissmann, 2000; Mitani, 1992). These functions would require more frequent vocal activity from males than what we find in $H$. moloch. Males of H. moloch roughly sing about once a week (Geissmann and Nijman, 2001), which is much less than other gibbons. For males of other gibbon species which do sing several times each week, no significant relationship was found between the frequencies of male solo song bouts and territorial conflicts; yet, these males are territorial and do provide physical defence of their territories. In contrast, territorial conflicts appear to correlate with the frequency of song bouts of mated females (Cowlishaw, 1992).

Cowlishaw (1996) suggested that gibbon males (but not females) use assessment signals to advertise resource-holding potential. Whitten (1984a, b) suggested that male songs of H. klossii (but not female songs) follow the handicap principle (e.g. Zahavi, 1975; Zahavi and Zahavi, 1998) by requiring a lot of energy and stamina of the singer. The songs would then be an honest signal declaring the singer's fitness and his con- fidence and willingness to defend his territory. This hypothesis is supported by the observation that male Kloss's gibbons tend to maximise their vocal output by singing about twice as often as females (about once every 1.7-2.5 days) and by spending over seven times as much time singing as females. In addition, males sing earlier in the morning than females. They produce most of their songs before dawn (Tenaza, 1976; Whitten, 1984b), at a time when most diurnal mammals try to reduce their energy expenditure.

In H. klossii and other members of the genus Hylobates, male solo songs have a longer duration and tend to occur earlier in the morning than female or duet songs (Geissmann, 2000). These observations partially apply to $H$. moloch, as well. Whereas an average female solo song bout of H. moloch has a duration of about 7 minutes (Geissmann and Nijman, 2001), the six complete male solo song bouts we analysed had an average duration of 23 minutes. This average does not even include the longest recording of our study (40 min $45 \mathrm{~s}$ ), because that song bout was not completely recorded. Recent field observations in Central Java also document that most male songs start before dawn when it is still dark, whereas most female songs start after dawn (Geissmann and Nijman, 2001).

The analogy to the Kloss's gibbon does not extend, however, to the frequency of male singing. The field observations in Central Java (Geissmann and Nijman, 2001), as well as our observations in Howletts, suggest that males sing only about once per week, whereas females sing about ten times as often. This appears to be a reversal of the rule that, in the majority of territorial species, it is the male that calls and defends the territory (Clutton-Brock and Harvey, 1977). It is questionable whether 30 minutes of singing once a week represent a suitable handicap by which a male gibbon can advertise his fitness.

None of the functions suggested for gibbon songs so far appear to explain satisfactorily the rarity and variability of the male song of H. moloch. It is difficult to find a plausible explanation for an event which occurs so rarely. It is also difficult to assess the biological relevance of the high variability we found in note type structure and phrase structure of male silvery gibbons.

Preferences for certain note types and for certain phrase syntax both appear to differ among 
male silvery gibbons, although it is unknown whether the gibbons individually recognise each others' songs. Bornean gibbons ( $H$. muelleri) did not respond differentially to experimental playbacks of their own, neighbours', and strangers' duets (Mitani, 1985). The author concluded, however, that failure to show vocal discrimination may be due to factors associated with the experimental procedure (e.g. playback periods lasted only 3 minutes) or may indicate that there is no selective advantage gained by responding differentially under the playback procedure.

\section{New functional hypotheses}

Even if inter-individual variability serves to facilitate individual recognition, this does not explain the adaptive value of high intra-individual variability.

Why should males produce stereotyped phrases in some gibbon species and highly variable phrases in other species? Without knowing the adaptive values of variable versus stereotyped male songs, it is plausible to assume that at least one of the two strategies provides a selective advantage to the singer. Therefore, two alternate views can be compared: (1) There may be a selective advantage for gibbon males to produce stereotyped phrases, but - for unknown reasons selection became secondarily relaxed in the silvery gibbon. (2) The opposite is true: intraindividual variability has been highly selected for in the songs of silvery gibbons, but at unknown costs. Of course, more complex intermediate solutions are also possible, but less easy to test.

Accordingly, a high degree of either song variability or song stereotypy could be used to advertise the singer's fitness to conspecifics (potential mates or potential competitors). In order to qualify as a handicap (Zahavi, 1975; Zahavi and Zahavi, 1997), the feature in question must involve costs, otherwise it could not be used to signalise fitness. Either song type could qualify as an honest "handicap" signal according to the handicap principle, because neither variability nor stereotypy could be "forged", provided that they come with a cost. But which of the two character states is the cost-intensive one? As a proximate mechanism, variability could be either result from an easily created randomness or from complex variability generator. Likewise, stereotypy could require a complex mechanism to countereffect entropy, or else it could represent formulaic repetition of a simple code.
Fitch et al. (2002) recently suggested that nonlinearities in the peripheral vocal production system of many primates and other mammals "allows individuals to generate highly complex and unpredictable vocalizations without requiring equivalently complex neural control mechanisms." Although we do not think that the unusually high intra- and inter-individual variability of the male song in $\mathrm{H}$. moloch are related to the non-linear phenomena described by Fitch et al. (2002), their paper is important in the context discussed here because it documents that vocal variability and unpredictability is not necessarily an "expensive" character state.

Here we present two different hypothesis which could explain how either song variability or song stereotypy produce costs to the singer. Both hypotheses can be used to generate predictions that can be tested in order to determine whether song variability or song stereotypy produce more costs.

Hypothesis 1: Singing may require not only muscle activity, but also brain activity, both of which consume energy. In this case, brain activity may represent a decisive cost-factor differentiating between a variable song and a stereotyped song. If the energy requirements of singing gibbons were determined (e.g. by measuring oxygen consumption), it could be tested which of the two song types uses more energy.

Hypothesis 2: It is well known to both gibbon hunters and gibbon observers that approaching wild gibbons is easier when they are singing than when they are silent. The concentration required to produce song phrases may represent a decisive investment provided by a gibbon. A more concentrated or focused singer should be more vulnerable because he could be surprised by predators or competitors more easily because he may pay less attention to potentially dangerous sounds or movements in his environment. The question is: What requires more attention from a singer, producing stereotyped phrase or producing more loosely organised variable phrases? The two alternatives could be tested, for instance, by presenting increasingly loud or long noise stimuli to singing gibbons. The concentration of the singer could be determined by the minimum stimulus duration or loudness required to be noticed by the gibbon (as estimated by his responses such as song interruption or song abortion). This would represent an estimate of the singer's concentration.

Both hypothesis can, in principle, be tested, and 
the results would help to narrow down the possible functions of singing in male gibbons. If, for instance, the extremely variable songs of the male silvery gibbon were found to be more costintensive than the more stereotyped songs of other gibbon species, this could explain why silvery gibbons sing less often and why their rare songs can still serve to advertise fitness. If the more stereotyped songs of male Kloss's gibbons are cheaper to produce, this would explain why they have to be produced more often in order to be enough of a handicap.

It has previously been suggested that gibbon songs - even within one species - serve more than one function (Geissmann, 1999; Geissmann and Orgeldinger, 2000). Results of the present study reveal a differential song variability occurring among the various gibbon species. This further supports the view that gibbon songs are multifunctional and that the relevance of these functions exhibits strong differences among the species. Expecting to discover "the song function" of "the gibbon" does not appear to be a realistic anymore.

\section{Conclusions}

1 The note repertoire of silvery gibbon males appears to exhibit a higher degree of interindividual variability than other gibbons.

2 The note repertoire of silvery gibbon males appears to exhibit a higher degree of intraindividual variability than other gibbons (both males and females).

3 The high variability of the male song in the silvery gibbon appears to be a derived characteristic among the Hylobatidae.

4 Male songs of $H$. moloch may function more to advertise individual fitness than ownership of resources.

5 Specific experiments are required in order to determine whether different costs are involved with producing variable versus stereotyped songs.

6 Gibbon songs probably serve multiple functions and these functions or their relevance differ among gibbon species.

\section{Acknowledgements}

Additional tape-recordings used in the present study were kindly made available by Dr. Markus Kappeler and Dr. Björn Merker. We are grateful to Dr. Robert Dallmann and two anonymous reviewers for reading and commenting on this manuscript.

\section{References}

Brockelman WY, Srikosamatara S. 1984. Maintenance and evolution of social structure in gibbons. In: Preuschoft H, Chivers DJ, Brockelman WY, Creel N, eds. The lesser apes. Evolutionary and behavioural biology. Edinburgh: Edinburgh University Press, 298-323.

Charif RA, Mitchell S, Clark CW. 1995. Canary 1.2 user's manual. New York: Cornell Laboratory of Ornithology, Ithaca.

Chivers DJ. 1977. The lesser apes. In: Prince Rainier III of Monaco, Bourne GH, eds. Primate conservation. New York: Academic Press, 539-598.

Chivers DJ. 2001. The swinging singing apes: Fighting for food and family in far-east forests. In Chicago Zoological Society, ed. The apes: Challenges for the 21 st century. Brookfield Zoo, May 10-13, 2000, Conference Proceedings. Brookfield, Illinois, U.S.A.: Chicago Zoological Society, 1-28.

Cowlishaw G. 1992. Song function in gibbons. Behaviour 121: 131-153.

Cowlishaw G. 1996. Sexual selection and information content in gibbon song bouts. Ethology 102: 272-284.

Clutton-Brock TH, Harvey PH. 1977. Primate ecology and social organization. J. Zool. 183: 1-39.

Dallmann R, Geissmann T. 2001a. Different levels of variability in the female song of wild silvery gibbons (Hylobates moloch). Behaviour 138: 629-648.

Dallmann R, Geissmann T. 2001b. Individuality in the female songs of wild silvery gibbons (Hylobates moloch) on Java, Indonesia. Contrib. Zool. 70: 41-50.

Demars C, Goustard M. 1978. Le "grand chant" d'Hylobates concolor leucogenys. Comparaison avec les émissions sonores homologues d'H. concolor gabriellae et d'H. klossii (Îles Mentawei, ouest Sumatra). Behaviour 65: 1-26 (French text, English summary).

Fitch WT, Neubauer J, Herzel H. 2002. Calls out of chaos: The adaptive significance of nonlinear phenomena in mammalian vocal production. Anim. Behav. 63: 407-418.

Geissmann T. 1993. Evolution of communication in gibbons (Hylobatidae). PhD thesis, Anthropological Institute, Philosoph. Faculty II, Zürich University, 374 pp.

Geissmann T. 1995. Gibbon systematics and species identification. Int. Zoo News 42: 467-501.

Geissmann T. 1999. Duet songs of the siamang, Hylobates syndactylus: II. Testing the pair-bonding hypothesis during a partner exchange. Behaviour 136: 1005-1039.

Geissmann T. 2000. Gibbon songs and human music from an evolutionary perspective. In: Wallin NL, Merker B, Brown $\mathrm{S}$, eds. The origins of music. Cambridge, Massachusetts: MIT Press, 103-123. 
Geissmann T. 2002a. Duet-splitting and the evolution of gibbon songs. Biol. Rev. 77: 57-76.

Geissmann T. 2002b. Taxonomy and evolution of gibbons. In: Soligo C, Anzenberger G, Martin RD. eds. Anthropology and primatology into the third millennium: The Centenary Congress of the Zürich Anthropological Institute (Evolutionary Anthropology Vol. 11, Supplement 1) (pp. 28-31). New York: Wiley-Liss.

Geissmann T, Dallmann R. 2002. Die Gesänge der Gibbons und die Evolution der Musik. Praxis der Naturwissenschaften - Biologie in der Schule 51(1): 21-29 (German text).

Geissmann T, Nijman V. 2001. Calling behaviour of wild Javan gibbons Hylobates moloch in Java, Indonesia. In: Nijman, V, ed. Forest (and) primates: Conservation and ecology of the endemic primates of Java and Borneo. Tropenbos-Kalimantan Series Vol. 5. Wageningen, The Netherlands: Tropenbos International, pp. 43-59.

Geissmann T, Orgeldinger M. 2000. The relationship between duet songs and pair bonds in siamangs, Hylobates syndactylus. Anim. Behav. 60: 805-809.

Gittins SP, Raemaekers JJ. 1980. Siamang, lar and agile gibbons. In: Chivers DJ, ed. Malayan forest primates Ten years' study in tropical rain forest. New York: Plenum Press, pp. 63-105.

Goustard M. 1976. The vocalizations of Hylobates. In: Rumbaugh DM, ed. Gibbon and siamang, vol. 4. Basel and New York: Karger, pp. 135-166.

Haimoff EH. 1983. Gibbon songs: An acoustical, organizational, and behavioural analysis. $\mathrm{PhD}$ thesis, University of Cambridge, pp. xxiii+412 pp.

Haimoff EH. 1984a. Acoustic and organizational features of gibbon songs. In: Preuschoft H, Chivers DJ, Brockelman WY, Creel N, eds. The lesser apes. Evolutionary and behavioural biology. Edinburgh: Edinburgh University Press, pp. 333-353.

Haimoff EH. 1984b. The organization of song in the agile gibbon (Hylobates agilis). Folia Primatol. 42: 42-61.

Haimoff EH. 1985. The organization of song in Müller's gibbon (Hylobates muelleri). Int. J. Primatol. 6: 173-192.

Haimoff EH, Tilson RL. 1985. Individuality in the female songs of wild Kloss' gibbons (Hylobates klossii) on Siberut Island, Indonesia. Folia Primatol. 44: 129-137.

Haimoff EH, Gittins SP. 1985. Individuality in the songs of wild agile gibbons (Hylobates agilis) of Peninsular Malaysia. Am. J. Primatol. 8: 239 - 247.

Kappeler M. 1981. The Javan silvery gibbon (Hylobates lar moloch). PhD thesis, PhilisophischNaturwissenschaftliche Fakultät, Universität Basel.

Kappeler M. 1984a. Vocal bouts and territorial maintenance in the moloch gibbon. In: Preuschoft $\mathrm{H}$, Chivers DJ, Brockelman WY, Creel N, eds. The lesser apes. Evolutionary and behavioural biology. Edinburgh: Edinburgh University Press, 376-389.

Kappeler M. 1984b. The gibbon in Java. In: Preuschoft H, Chivers DJ, Brockelman WY, Creel N, eds. The lesser apes. Evolutionary and behavioural biology. Edinburgh: Edinburgh University Press, 19-31.

Leighton DR. 1987. Gibbons: Territoriality and monogamy. In: Smuts BB, Cheney DL, Seyfarth RM, Wrangham RW, Struhsaker TT, eds. Primate societies. Chicago and London: University of Chicago Press, 135-145.
Marshall JT, Marshall ER. 1976. Gibbons and their territorial songs. Science 193: 235-237.

Marshall JT, Sugardjito J. 1986. Gibbon systematics. In: Swindler DR, Erwin J, eds. Comparative primate biology, vol. 1: Systematics, evolution, and anatomy. New York: Alan R. Liss, 137-185.

Mitani JC. 1985. Responses of gibbons (Hylobates muelleri) to self, neighbor, and stranger song duets. Int. J. Primatol. 6: $193-200$.

Mitani JC. 1988. Male gibbon (Hylobates agilis) singing behavior: Natural history, song variations and function. Ethology 79: 177-194.

Mitani JC. 1992. Singing behavior of male gibbons: Field observations and experiments. In: Nishida T, McGrew WC, Marler P, Pickford M, deWaal FBM, eds. Topics in primatology, vol. 1: Human origins. Tokyo: University of Tokyo Press, 199-210.

Mitani JC, Marler P. 1989. A phonological analysis of male gibbon singing behavior. Behaviour 109: 20-45.

Mitani JC, Gros-Louis J, Macedonia JM. 1996. Selection for acoustic individuality within the vocal repertoire of wild chimpanzees. Int. J. Primatol. 17: 569-583.

Raemaekers JJ, Raemaekers PM, Haimoff EH. 1984. Loud calls of the gibbon (Hylobates lar): Repertoire, organization and context. Behaviour 91: 146-189.

Roos C, Geissmann T. 2001. Molecular phylogeny of the major hylobatid divisions. Molec. Phylogen. Evol. 19: 486-494.

Snowdon CT. 1986. Vocal communication. In: Mitchell DR, Erwin J, eds. Comparative primate biology, vol. $2 \mathrm{~A}$ : Behavior, conservation, and ecology. New York: Alan R. Liss, 495-530.

Tenaza RR. 1976. Songs, choruses and countersinging among Kloss' gibbons (Hylobates klossi) in Siberut island, Indonesia. Z. Tierpsychol. 40: 37-52.

Waser PM. 1982. The evolution of male loud calls among mangabeys and baboons. In: Snowdon CT, Brown $\mathrm{CH}$, Petersen MR, eds. Primate communication. Cambridge: Cambridge University Press, 117-143.

Whitten AJ. 1980. The Kloss gibbon in Siberut rain forest. Ph.D. thesis, Sub-Department of Veterinary Anatomy, University of Cambridge.

Whitten T. 1982. The ecology of singing in Kloss gibbons (Hylobates klossii) on Siberut Island, Indonesia. Int. J. Primatol. 3: 33-51.

Whitten T. 1984a. Defense by singing. Great calls and songs of the Kloss gibbon. In: MacDonald $\mathrm{D}$, ed. The encyclopedia of mammals, vol. 1. London: Allen and Unwin, 420-421.

Whitten AJ. 1984b. The trilling handicap in Kloss gibbons. In: Preuschoft H, Chivers DJ, Brockelman WY, Creel N, eds. The lesser apes. Evolutionary and behavioural biology. Edinburgh: Edinburgh University Press, 416-419.

Zahavi A. 1975. Mate selection - a selection for a handicap. J. Theoret. Biol. 53: 205-214.

Zahavi A, Zahavi A. 1997. The handicap principle: A missing piece of Darwin's puzzle. New York and Oxford: Oxford University Press.

Received: 28 March 2003

Accepted: 16 September 2004 


\section{Appendix}

Consecutive sonagrams of a complete (and relatively short) male solo song bout of male "Paul". This is the song bout identified as Munich 1a in Table 1. The song bout has a duration of about 12 minutes. It begins with simple, very soft single hoots (oo notes). Later in the song bout, starting with line 3 , the oo notes are gradually replace by louder wa notes. By the end of part 1 , wa notes are gradually combined to phrases, and other note types are added. In lines 11-14, the gibbon's song motivation appears to decline temporarily. After this, the male builds up his phrases anew, starting with soft hoots again (lines 15-17). This second build-up phase proceeds faster than at the beginning of the song bout. The song bout ends abruptly as a great-call phrase of a female white-cheeked crested gibbon (Nomascus leucogenys) begins in the background (this is the begin of a duet song bout of the crested gibbons). The female phrase is blurred in the sonagram because of echo effects occurring in the indoor cage. (The crested gibbon pair is kept in an indoor cage adjacent to the island inhabited by the silvery gibbon pair.)

Whenever the intensity of the gibbon calls was very low, the sensitivity of the tape-recorder was increased during the recording. As a result, the background noise increases in some sections of the tape-recording, resulting in a grey background in some of the sonagrams.

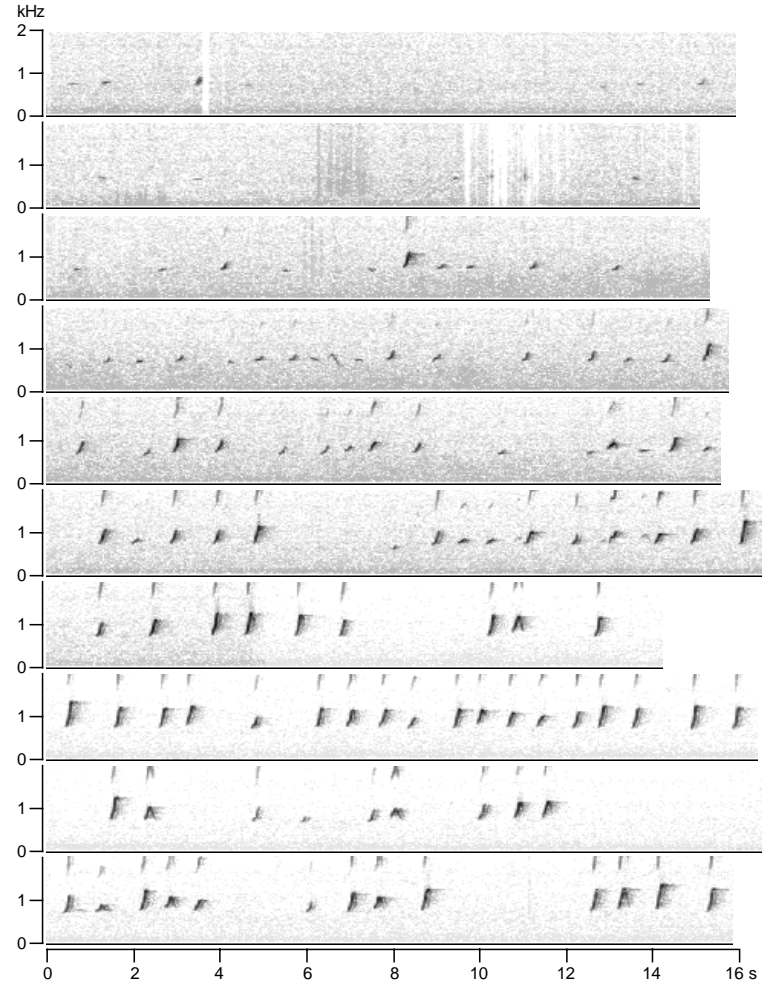

Appendix part 1

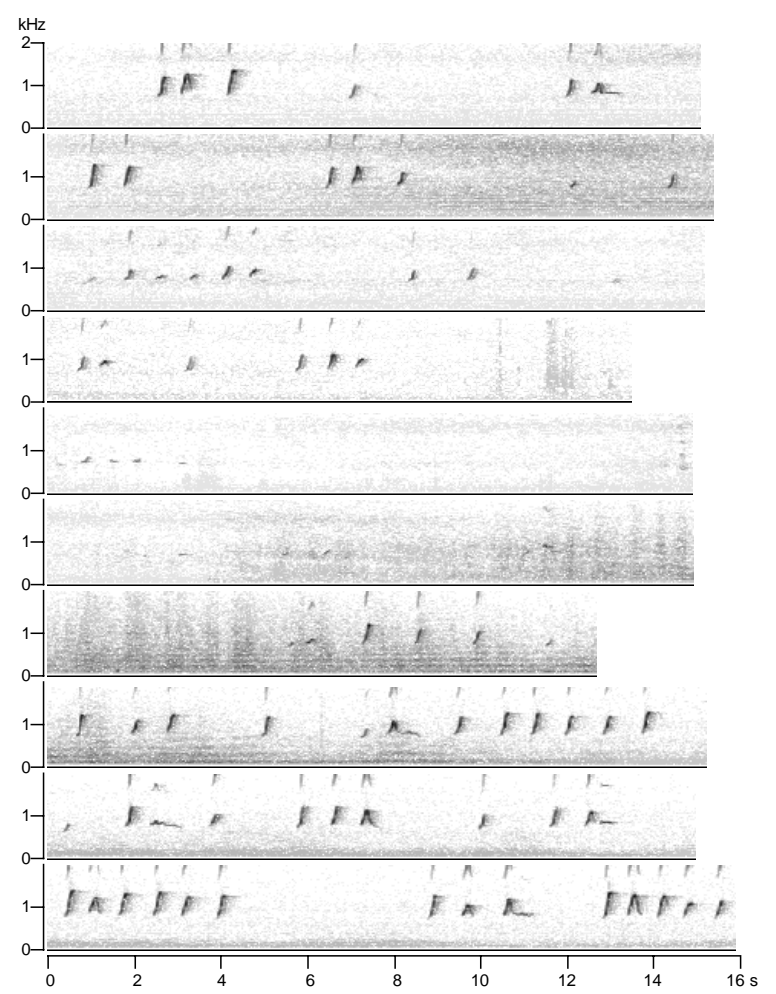

Appendix part 2 
Contributions to Zoology, 74 (1/2) - 2005

25

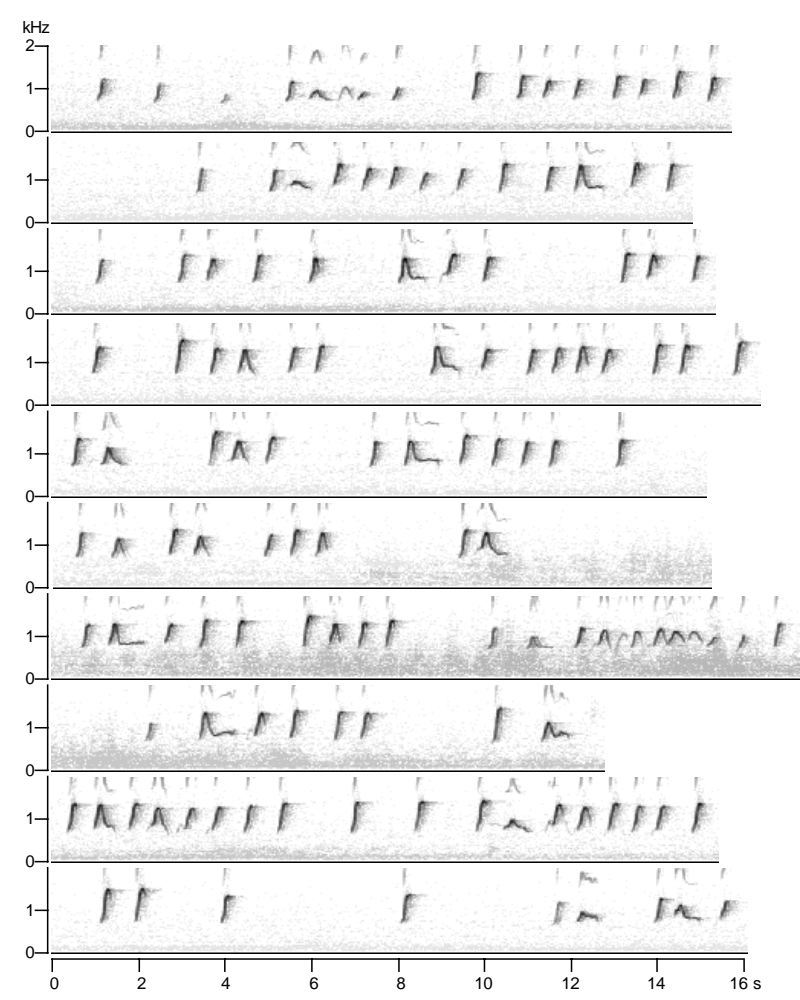

Appendix part 3

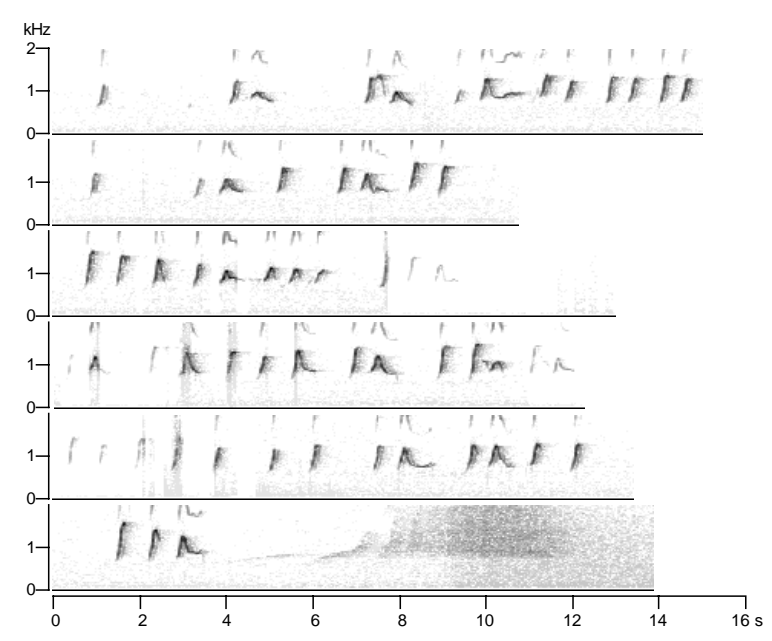

Appendix part 5

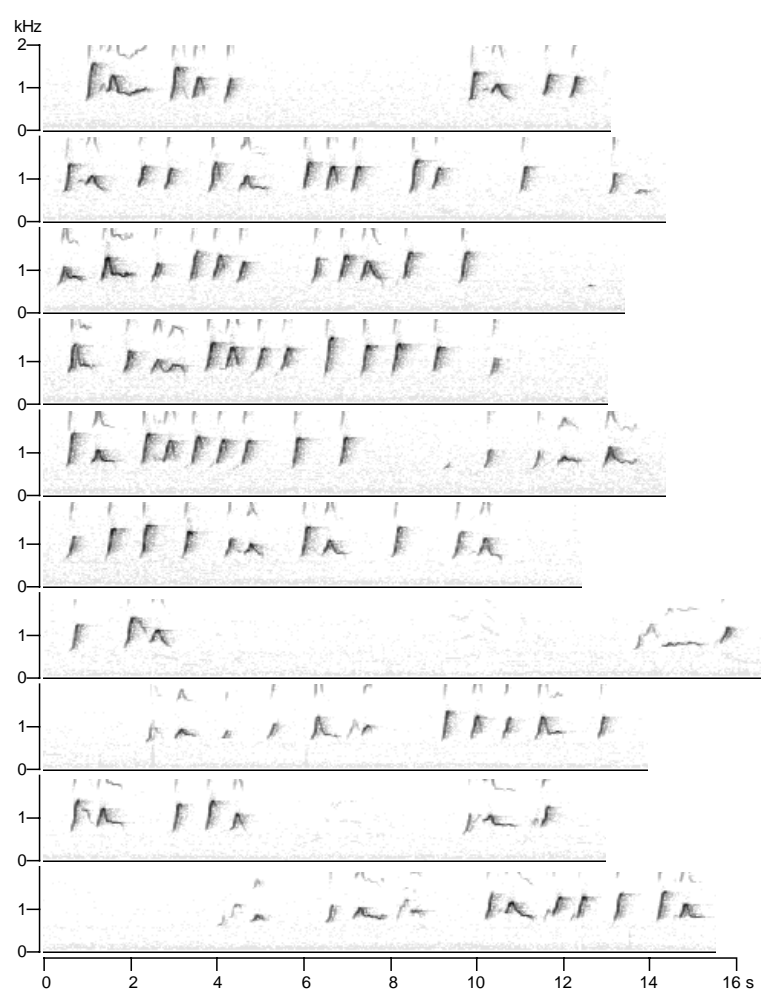

Appendix part 4 